\title{
Impact of Vegetation Leaf Area Change on Global Terrestrial Water Storage in Recent 30 Years Based on GRACE and Reconstruction Data
}

Tao Hong ( $\sim$ ht@mail.bnu.edu.cn )

Civil Aviation Flight University of China https://orcid.org/0000-0001-6569-8698

\section{Xianbiao Kang}

Civil Aviation Flight University of China

Junjie Wu

Civil Aviation Flight University of China

\section{Min Yuan}

Civil Aviation Flight University of China

\section{Yunfeng Liu}

Civil Aviation Flight University of China

\section{Research Article}

Keywords: Vegetation, Leaf area index, Terrestrial water storage, GRACE, GRACE-REC

Posted Date: February 18th, 2021

DOl: https://doi.org/10.21203/rs.3.rs-203841/v1

License: (9) This work is licensed under a Creative Commons Attribution 4.0 International License. Read Full License 
Impact of vegetation leaf area change on global terrestrial water storage in recent 30 years based on GRACE and reconstruction data

Tao Hong ${ }^{1}$, Xianbiao Kang ${ }^{1}$, Junjie Wu*1, Min Yuan ${ }^{1}$, Yunfeng Liu ${ }^{1}$

${ }^{1}$ Civil Aviation Flight University of China, Sichuan, China

*Corresponding author: Junjie Wu, 434947397@qq.com, +8618981026947 


\begin{abstract}
Vegetation change has an important impact on land water cycle by changing transpiration and other water exchange between land and atmosphere. Terrestrial water storage (TWS) is an important component of global water cycle and freshwater resources. However, the impact of vegetation change on terrestrial water storage under the background of global climate change is still unclear. Based on the GRACE satellite observed and GRACE-REC reconstructed global terrestrial water storage data, this study investigated the impact of global vegetation leaf area change on terrestrial water storage in recent 30 years. The results show that there is a significant positive correlation between leaf area index (LAI) and terrestrial water storage in the demandlimited region. The sensitivity of TWS on LAI change is high mainly in Australia, central and southern Africa, South Asia, Mediterranean region, western United States, southern South America and other regions with high temperature and low precipitation, and the analysis of GRACE-REC shows the sensitivity in demand-limited region has an increasing trend. Compared with climate factors such as temperature and precipitation, the TWS trend caused by LAI is nearly the same, and has the same sign (all positive or all negative) as that of originally TWS in about $63.6 \%$ global land area, and the LAI-related TWS trend is high in the region with annual average precipitation of $500-1000 \mathrm{~mm}$. In the six different global land cover classes, the sensitivity of TWS to the LAI change is much higher in semi-arid, grass cop, sparsely vegetated regions, and LAI plays an important role in the interannual variations of TWS in semi-arid, grass cop regions. This study emphasizes the important role of vegetation change in the land water cycle, which is of great significance to the management and utilization of water resources in the future, especially in the arid and semi-arid regions.
\end{abstract}

Keywords: Vegetation, Leaf area index, Terrestrial water storage, GRACE, GRACE-REC 


\section{Introduction}

Land vegetation change alter $\mathrm{CO} 2$ absorption, evaporation and land surface albedo, and then the exchange of carbon, energy and water flux between land and atmosphere, has an important impact on climate (Chapin et al., 2008; Bonan et al., 2008). Vegetation transpiration, as the largest amount of land evaporation (Jasechko et al., 2013), plays an important role in regulating the global land water cycle, and the evaporation change caused by vegetation greening plays a fundamental role in the interaction between vegetation and land water cycle (Zeng et al., 2018a).

Vegetation change has an important impact on the components of land water cycle. Studies have shown that the recent increase trend of global evaporation is mainly driven by vegetation greening (Zeng et al., 2018b). Observation studies have also pointed out that compared with climate change, the impact of large-scale vegetation change on global runoff change cannot be ignored (Wei et al., 2018), although precipitation is the main factor that determining runoff change, the extension of vegetation growing season also induced significant regional runoff change (Geng et al., 2020). Model studies also show that global vegetation greening has an important impact on global and regional water cycle components such as evaporation, precipitation, runoff and soil moisture (Zeng et al., 2018b; Yue Li et al., 2018).

In addition, the effect of increasing $\mathrm{CO} 2$ concentration on vegetation also alter the land surface water cycle. The increasing $\mathrm{CO} 2$ concentration increases the vegetation leaf area and transpiration, and also increases the water use efficiency of vegetation which may reduce the impact of drought caused by climate change, these two effects are offset. Studies show that the combined effect of the two effects has an important impact on the land surface water cycle (Lemordant et al., 2018; Cheng et al., 2017; Hong et al., 2019). Observational studies indicate that the response of vegetation in semi-arid and semi-humid areas of Australia to the increase of $\mathrm{CO} 2$ concentration in the past 30 years leads to decrease of evaporation, increase of runoff (Ukkola et al., 2016), and the decrease of base flow (Trancoso et al., 2017). The model results show that the vegetation response to rising $\mathrm{CO} 2$ concentration reduces transpiration and cloud 
cover, and the dry boundary layer reduces the possibility of rainfall and increases the frequency of drought (Skinner et al., 2017, 2018). The projection of the earth system model also shows that as the continuous increase of $\mathrm{CO} 2$ concentration, the vegetation leaf area and water use efficiency change may play an important role in evaporation and runoff change in the future (Lemordant et al., 2018; Mankin et al., 2018; Kooperman et al., 2018; Fowler et al., 2020; Cui et al., 2020).

Terrestrial water storage includes groundwater, soil moisture, surface water such as rivers and lakes, snow and ice, plays an important role in the global water cycle and freshwater resources, and the change of terrestrial water storage is increasingly concerned (Wang et al., 2020; Wang et al., 2018; Cao et al., 2019). The terrestrial water storage is mainly affected by precipitation, evaporation, runoff, snowmelt and other land surface water cycle components (Humphrey et al., 2017; Rodell et al., 2018; Mankin et al., 2019; Cuthbert et al., 2019; Wu et al., 2020; Zhang et al., 2019), some studies have assessed the significant impact of climate change or internal variability of large-scale climate systems such as ENSO on terrestrial water storage (Ni et al., 2018; Anyah et al., 2018; Thomas et al., 2019). Although terrestrial water storage change is dominated by precipitation, many studies show that glacier retreat, lake expansion, groundwater exploitation and some other human activities also have a great impact on terrestrial water storage (Xu et al., 2019; Tao et al., 2020; Ndehedehe et al., 2020; Chaudhari et al., 2019).

In addition, some studies have revealed the impact of vegetation change on terrestrial water storage, and found a interaction between groundwater and vegetation in global vegetation covered areas (Koirala et al., 2017), and the increase of vegetation leaf area reduces the tendency of dryland soil and groundwater drying (Deng et al., 2020; Han et al., 2020).

Considering the important impact of vegetation on land surface water cycle, and the facts that vegetation atmospheric feedback exists widely in the world (Green et al., 2017) and there has been vegetation greening in a large area of the global land in recent 30 years (Zhu et al., 2016), hence the impact of such large-scale vegetation greening on 
terrestrial water storage is worthy of further study. Due to the large uncertainty of land surface model and earth system model in the simulation of terrestrial water storage and vegetation atmosphere feedback (Jensen et al., 2019; Green et al., 2017), satellite observations of terrestrial water storage are very important to further constrain the response of the land water cycle to climate change. With the availability of GRACE (Gravity Recovery and Climate Experiment) global satellite observed terrestrial water storage data (Tapley et al., 2019), the impact of global vegetation leaf area change on terrestrial water storage can be analyzed.

This study aims to investigate the impact of vegetation changes on global terrestrial water storage revealed by satellite observations. The temporal and spatial responses of terrestrial water storage to global vegetation change were investigated by using the vegetation leaf area index (LAI), GRACE terrestrial water storage (TWS) data observed by satellite, and GRACE-REC the reconstructed long time series of terrestrial water storage data. This paper investigates the following issues: (1) spatial distribution and temporal variation of the sensitivity of terrestrial water storage to vegetation leaf area change. (2) relative influence of change of vegetation leaf area on terrestrial water storage, compared with temperature and precipitation. (3) the influence of vegetation in different land cover areas on terrestrial water storage, find out the regions where vegetation has most significant impact.

\section{Materials and methods}

\subsection{Data}

Terrestrial water storage (TWS):

GRACE: The global TWS data were obtained from the JPL RL06Mv2 mascon solution - with CRI filter applied (version JPL GRACE and GRACE-FO MASCON RL06Mv2 CRI) produced by the Jet Propulsion Laboratory of NASA (Watkins et al., 2015; Wiese et al.,2016). The monthly TWS variations data span from April 2002 to Dec 2016 were used in this study, and the spatial resolution is 0.5 degrees. 
GRACE-REC (GRACE reconstruction): The global monthly reconstructed TWS from 1982-2016 were obtained from GRACE reconstruction (Humphrey et al 2019), We use JPL_MSWEP dataset from GRACE-REC which trained with GRACE JPL mascons, forced with MSWEP (multisource weighted-ensemble precipitation) dataset (1979-2016).

The satellite-based LAI products from 1982-2016 were obtained from NOAA Climate Data Record (TCDR v5, https://www.ncei.noaa.gov/data/avhrr-land-leafarea-index-and-fapar/access/), and the spatial resolution is 0.5 degrees. The Climatic Research Unit (CRU) temperature and precipitation with 0.5-degree spatial resolution gridded data were used to calculate the sensitivity of GRACE on LAI change. To consistent with GRACE-REC (Humphrey et al 2019), we use MSWEP precipitation and ERA5 air temperature dataset to calculate the sensitivity of GRACE-REC on LAI change.

\subsection{Methods}

\subsubsection{Compute the sensitivity of TWS to LAI change}

The sensitivity of TWS to LAI change was computed as the partial derivative that results from a multiple linear regression (1), relating the annual averaged terrestrial water storage change $(\triangle T W S)$ to annual averaged LAI $(\triangle L A I)$, annual averaged precipitation $(\Delta P)$, annual averaged temperature $(\Delta T)$, and the annual cycle of all variables has been removed. The calculation excludes the influence of temperature and precipitation on TWS, and the independent effect of LAI was obtained. In addition, the method assumes that each factor is independent of each other and does not consider the influence of other factors such as human activities.

$\Delta T W S=\beta_{0}+\frac{\partial T W S}{\partial L A I} \Delta L A I+\frac{\partial T W S}{\partial P} \Delta P+\frac{\partial T W S}{\partial T} \Delta T$ 
In order to investigate the long-term change of TWS sensitivity to LAI change, (1) is used to compute the sensitivity of 7-year and 12-year sliding intervals of GRACE-REC to LAI change from 1982 to 2016. And to reduce the statistical error, the sensitivity of each grid point is calculated in the $3 \times 3$ grid area with the grid point as the center.

Using the sensitivity of TWS to LAI change and the local LAI trend, the TWS trend caused by LAI change ( $\left.\delta T W S^{L A I}\right)$ is computed as (2), where $\delta L A I$ is the longterm trend of LAI, $\frac{\partial T W S}{\partial L A I}$ is the sensitivity of TWS to LAI change.

$$
\delta T W S^{L A I}=\frac{\partial T W S}{\partial L A I} \delta L A I
$$

\subsubsection{Reconstruction of LAI-related TWS time series}

Referring to Forzieri (2017), the time series of LAI related TWS is reconstructed by using the sensitivity of TWS to LAI change and the LAI year-to-year variations. The reconstructed TWS time series is expressed as the change relative to the first year TWS, reflecting the interannual variations of TWS caused by the LAI year-to-year variations.

\subsubsection{Demand-limited, Supply-limited region and Land cover classes}

Referring to Forzieri (2020), the correlation between latent heat flux (LE) and temperature $(\mathrm{T})$, and correlation between LE and precipitation $(\mathrm{P})$ are compared to divide global land into demand-limited region (cor(LE,P)<cor(LE,T)) or supplylimited region (cor(LE,P) $>\operatorname{cor}(\mathrm{LE}, \mathrm{T}))$, and the latent heat flux, precipitation and temperature data are form ERA5.

Land cover maps are retrieved from MODIS(MCD12C1, https://lpdaac.usgs.gov/products/mcd12c1v006/), referring to Ahlström (2015), We defined six land cover classes covering the global land area: tropical forest, extra- 
tropical forest (boreal and temperate), semi-arid ecosystems, tundra and arctic shrub land, grasslands and crops, and sparsely vegetated.

\section{Results}

3.1 Relationship between global terrestrial water storage (TWS) and vegetation leaf area index (LAI)

Fig1 shows the spatial distribution of the composite mean terrestrial water storage corresponding to the top 5\% of the largest and the bottom $5 \%$ of the minimum value of vegetation leaf area index. The composite mean GRACE terrestrial water storage observed from 2002 to 2016 shows that when LAI was low, most of the terrestrial water storage was relatively low in the middle and high latitudes of the northern hemisphere, North China, southern United States, southern South America and Australia (Fig. 1a), while the TWS was significantly higher in most of the above regions, central and Eastern Europe and central and eastern North America when LAI was high (Fig. 1b), indicating that there may be a positive correlation between vegetation leaf area and terrestrial water storage in these regions, which is generally consistent with the spatial distribution of correlation between TWS and LAI (Suppl Fig 1). And when LAI was low, TWS was high in South Asia and Central Africa, and vice versa (Fig1. a,b). The spatial distribution of composite mean GRACE-REC (reconstructed longer time series of TWS) from 1982 to 2016 is generally consistent with that of GRACE satellite observation (Fig1 c,d), except for difference response in some regions of the northern hemisphere middle and high latitudes. The above results indicate that the LAI may have a significant correlation with terrestrial water storage.

In order to further explore the impact of LAI change on global TWS, according to the method in Forzieri (2020), by comparing the correlation of latent heat with precipitation and temperature, the global land is divided into supply-limited and demand-limited regions. The LAI and TWS in the demand-limited region has a larger correlation from 2002 to 2016, while the correlation between LAI and TWS in the 
supply-limited area is small (Fig2 a,b), and the demand-limited region (Suppl Fig 2) is generally consistent with the spatial distribution in the Fig1, where the most significant impact of LAI is mainly in Australia, southern Africa, southern South America and other arid regions. The GRACE-REC reconstructed long time series TWS and LAI are also highly correlated in the demand-limited region with the correlation coefficient of 0.44 and less correlated in the supply-limited region (Fig2 c,d). The above results indicate that the LAI may have a close relationship with TWS in the demand-limited region.

\subsection{Sensitivity analysis of TWS to LAI change}

Further analysis of the effects of temperature, precipitation and LAI on TWS, the sensitivity of TWS on LAI change was investigated. Fig 3a shows the spatial distribution of sensitivity of GRACE to LAI change from 2002 to 2016, it can be seen that the regions with high positive sensitivity are mainly located in Australia, South Asia, Mediterranean region, southern Africa, western North America, and there are small regions with low negative sensitivity, mainly in the middle and high latitudes of the northern hemisphere. The spatial distribution of sensitivity of GRACE-REC reconstructed TWS on LAI from 1982 to 2016 (Fig 3b) is generally consistent with GRACE, but the sensitivity is higher. And the latitude mean sensitivity is generally positive in all latitude (Fig3 c,d). In conclusion, the above results indicate that the sensitivity of TWS on LAI change is high mainly in the subtropical region of the northern and southern hemisphere where the increase of LAI may increase TWS, and the sensitivity is low in the high and low latitude regions.

Further analysis the relationship between the sensitivity of TWS on LAI change and the median of local annual mean temperature and annual total precipitation, it shows that during 2002-2016 the sensitivity is high in low precipitation regions, especially in high temperature and low precipitation regions (Fig $4 \mathrm{a}$ ), and there are some anomalous high sensitivity in low temperature regions of middle and high latitudes. In the GRACE-REC, the sensitivity is high in high temperature and low 
precipitation regions (Fig $4 \mathrm{~b}$ ), generally consistent with the spatial correlation distribution in Fig1, which shows the TWS and LAI in high temperature and low precipitation regions such as Australia, southern South America and southern Africa are highly correlated.

Based on GRACE-REC the long time series of reconstructed TWS data from 1982 to 2016, the temporal variation of sensitivity of TWS to LAI was further investigated. The moving average sensitivity of TWS on LAI over 7 and 12 years sliding were computed, and the trend of the moving average sensitivity of supplylimited and demand-limited regions were investigated. The results show that the moving average sensitivity of 7-year sliding in demand-limited region has an increase trend (Fig. 5a), and has no significant trend in supply-limited region, the overall global average sensitivity has a slight increasing trend. The trend of 12-year sliding moving average sensitivity is similar to that of 7-year (Fig 5b). These results indicate that the sensitivity of TWS to LAI changes in demand-limited region has increased, that is, the impact of LAI on TWS changes in demand-limited region were enhanced over recent 30 years, which means LAI may play a more important role in the regional TWS changes.

\subsection{The impact of LAI on TWS trend}

The sensitivity of TWS to LAI change and LAI trend are integrated to derived the trend of TWS caused by LAI (2). Fig $6 \mathrm{~b}$ shows the spatial distribution of TWS trend caused by LAI change. It can be seen that the regions with large LAI-related TWS trend are located in Australia, South Asia, North China, Europe, and regions with large TWS sensitivity to LAI change (Fig 3b), the trend of LAI is low in these areas, so the trend of TWS caused by LAI is not as significant as the sensitivity. Compare with the original TWS trend, the LAI-related TWS trend is small, and there are some areas with negative TWS trend, indicating that temperature and precipitation may have an impact in these regions, Supplemental Fig $3 \mathrm{~b}$ shows that the increase temperature decrease the TWS in western North America, Central Africa, South 
America and other regions, and because precipitation dominate the TWS change, the spatial pattern of TWS trend caused by precipitation is similar to that of original TWS (Supplemental Fig 3a). The above results show that the impact of LAI on TWS trend is mainly concentrated in Australia, South Africa and other demand-limited regions. The average original TWS trend and the TWS trend caused by LAI are generally all positive in most latitudes, and the magnitude are close, indicating that LAI has a great influence on TWS trend in most latitudes. Analysis the TWS trend caused by LAI and the local annual average temperature and annual total precipitation, the results differ from that the sensitivity of TWS to LAI is high in regions where annual total precipitation is less than $500 \mathrm{~mm}$ (Fig 4b), but the LAI-related TWS is high in regions where the annual total precipitation is $500-1000 \mathrm{~mm}$ (Fig. 7a), which indicates that the semi-arid region with annual precipitation of about $500 \mathrm{~mm}-1000 \mathrm{~mm}$ may be the region where LAI has the most significant impact.

The relative effects of precipitation, temperature and LAI on TWS trend were compared (Fig 8). The results show that the TWS trend caused by LAI is generally same magnitude to that caused by temperature and precipitation, and both the increased LAI and precipitation increases TWS in many regions, while the increased temperature mainly decreased TWS. In the demand-limited region, although the sensitivity of TWS to LAI change is high (Fig 8b), the TWS trend in the region is small (Fig 8c), so the overall trend of TWS caused by the LAI is small, while the LAI trend in the supply-limited region is large, thus the overall trend of TWS caused by the LAI is large. The above results indicate that the impact of LAI on TWS is comparable with that of temperature and precipitation. LAI-related TWS trend and original TWS trend have the same sign (all positive or all negative) in 63.6\% global land area, which indicates that LAI has a significant impact on global TWS trend.

\subsection{Impact of LAI on TWS in different regions}

In order to further distinguish the impact of LAI in different regions, the global land is divided into six regions (Fig 11): tropical tree, extra tropical tree, tundra shrub, 
sparsely vegetated, grass cross and semi-arid (Ahlstrüm et al., 2015). The results show that the TWS trend caused by LAI is large in three regions: gray cross, semi-arid and tunda shrub, the TWS trend caused by LAI is small in the sparsely vegetated region because the LAI change is very small in the region (Fig 9a), and the TWS trend caused by temperature and precipitation is also small in this region, indicated that the TWS may be mainly affected by other factors. In the grass crop and semi-arid regions, LAI change increase TWS, and the LAI-caused TWS change is larger than that caused by temperature and precipitation, which indicated that LAI played a significant role in these two regions, that generally consistent with the conclusion that LAI had a great impact in demand-limited region. In the tropical tree, extra tropical tree, tundra shrub and other supply-limited regions, the TWS trend caused by LAI are smaller than that caused by temperature or precipitation. In the tropical tree region, the warming decrease TWS strongly, which offset the positive impact of LAI in the region.

The sensitivity of TWS to temperature, precipitation and LAI show that the sensitivity of TWS on LAI is high in semi-arid, gray cross and sparsely vegetated regions, much higher than that in tropical tree, extra tropical tree and tundra shrub regions (Fig 9b). The sensitivity of TWS to precipitation is nearly close in each region, and relative larger in sparsely vegetated, extra tropical tree regions (Fig 9c). The regions with high negative sensitivity of TWS on temperature are mainly in tropical tree, semi-arid, and grade cross regions (Fig 9d), indicating that global warming would have a significant impact on TWS change in these regions in the future.

The time series of annual TWS change reconstructed based on LAI year-to-year variations are obtained. We integrated the sensitivity of TWS to LAI change and the year-to-year variations of LAI in semi-arid, gray cross, sparse vegetated regions, where LAI had significant correlation with TWS. The temporal variations of LAIreconstructed TWS of the three regions are analyzed respectively. The results show 
that in the semi-arid and grass crop regions, the interannual variations of original TWS and the TWS reconstructed by LAI is significantly correlated (Fig. 10a, b), with the correlation coefficients of 0.45 , although the interannual variations of original TWS is larger. In the sparsely vegetated region, although the sensitivity of TWS on LAI is high, the interannual variations of LAI is too small, and partly offsets the effect of LAI, which lead the interannual variations of LAI-reconstructed TWS quite different from that of original TWS (Fig. 10c), indicating the interannual variation of TWS in sparsely vegetated region may be dominated by other factors, such as precipitation.

\section{Conclusions}

In this study, the correlation between LAI and TWS, the sensitivity of TWS to LAI change, and the region where LAI has most significant impact on TWS are investigated, by using the LAI and GRACE TWS data from satellite and the GRACEREC reconstructed TWS data. The main conclusions are as follows: (1). Satellite observations show that there is a correlation between TWS and LAI, and most remarkable in the demand-limited region. (2). The sensitivity of TWS on LAI change is high mainly in Australia, South America, southern Africa, and high in climatology high temperature and low precipitation regions. The 7-year or 12-year moving average sensitivity of the GRACE-REC reconstructed TWS from 1982 to 2016 shows that the sensitivity of demand-limited region has an increase trend, indicating that the impact of LAI in this region has increased in recent 30 years. (3). Compare with temperature and precipitation, the extent of TWS trend caused by LAI is close, especially in the demand-limited regions such as Australia, South America and North America. And the LAI-related TWS trend is highest in the region with annual precipitation of 500-1000mm. (4). Further analysis of different land cover classes shows that the sensitivity of TWS to LAI is high in semi-arid, gray cross and sparse vegetated regions, much higher than other regions. Moreover, the interannual variations of TWS reconstructed by LAI in semi-arid and gray cross regions is much 
close to that of original TWS, indicates that LAI in these two regions has an important impact on TWS interannual variations. In conclusion, we emphasize the significant impact of LAI on TWS, and cannot be ignored compared to temperature and precipitation, also pointed out the regions where LAI have most significant impact, and emphasize the important role of land vegetation in management of land water resources in these areas in the future.

\section{Funding}

This study was funded by the Key Laboratory of Civil Aviation Flight Technology and Flight Safety of CAFUC research projects (FZ2020ZZ05), and Sichuan Science and Technology Program (2021JDRC0083).

\section{Competing interests}

The authors declare no competing interests.

\section{Author contributions}

T.H. designed the study. T.H. carried out the analysis and wrote the manuscript with contributions from X.K., J.W., the interpretation, final text and figures resulted from the contributions of all co-authors.

\section{References}

Ahlström A, Raupach M R, Schurgers G, et al. The dominant role of semi-arid ecosystems in the trend and variability of the land CO2 $\operatorname{sink}[\mathrm{J}]$. Science, 2015, 348(6237): 895-899.

Anyah R O, Forootan E, Awange J L, et al. Understanding linkages between global climate indices and terrestrial water storage changes over Africa using GRACE products[J]. Science of the Total Environment, 2018, 635: 1405-1416.

Bonan GB. Forests and Climate Change: Forcings, Feedbacks, and the Climate Benefits of Forests. Science. 2008;320(5882):1444-1449.

Cao Q, Clark E A, Mao Y, et al. Trends and Interannual Variability in Terrestrial Water 
Storage Over the Eastern United States, 2003-2016[J]. Water Resources Research, 2019, 55(3): 1928-1950.

Chapin FS, Randerson JT, McGuire AD, Foley JA, Field CB. Changing feedbacks in the climate-biosphere system. Frontiers in Ecology and the Environment. 2008;6(6):313-320.

Chaudhari S, Pokhrel Y, Moran E, et al. Multi-decadal hydrologic change and variability in the Amazon River basin: understanding terrestrial water storage variations and drought characteristics[J]. Hydrology \& Earth System Sciences, 2019, 23(7).

Cheng L, Zhang L, Wang Y-P, et al. Recent increases in terrestrial carbon uptake at little cost to the water cycle. Nature Communications. 2017;8(1).

Cui J, Piao S, Huntingford C, et al. Vegetation forcing modulates global land monsoon and water resources in a CO 2-enriched climate[J]. Nature communications, 2020, 11(1): $1-11$.

Cuthbert M O, Gleeson T, Moosdorf N, et al. Global patterns and dynamics of climategroundwater interactions[J]. Nature Climate Change, 2019, 9(2): 137-141.

Deng Y, Wang S, Bai X, et al. Vegetation greening intensified soil drying in some semiarid and arid areas of the world[J]. Agricultural and Forest Meteorology, 2020, 292 : 108103.

Forzieri G, Alkama R, Miralles DG, Cescatti A. Satellites reveal contrasting responses of regional climate to the widespread greening of Earth. Science. 2017;356(6343):11801184.

Forzieri G, Miralles DG, Ciais P, et al. Increased control of vegetation on global terrestrial energy fluxes. Nat Clim Chang. 2020;10(4):356-362.

Fowler M D, Kooperman G J, Randerson J T, et al. The effect of plant physiological responses to rising CO 2 on global streamflow[J]. Nature Climate Change, 2019, 9(11): 873-879.

Geng X, Zhou X, Yin G, et al. Extended growing season reduced river runoff in Luanhe River basin[J]. Journal of Hydrology, 2020, 582: 124538

Green JK, Konings AG, Alemohammad SH, et al. Regionally strong feedbacks between the atmosphere and terrestrial biosphere. Nature Geoscience. 2017;10(6):410-414.

Han Z, Huang S, Huang Q, et al. Effects of vegetation restoration on groundwater drought in the Loess Plateau, China[J]. Journal of Hydrology, 2020, 591: 125566. 
Hong T, Dong W, Ji D, et al. The response of vegetation to rising CO 2 concentrations plays an important role in future changes in the hydrological cycle[J]. Theoretical and Applied Climatology, 2019, 136(1): 135-144.

Humphrey V, Gudmundsson L, Seneviratne S I. A global reconstruction of climatedriven subdecadal water storage variability[J]. Geophysical Research Letters, 2017, 44(5): 2300-2309.

Humphrey V, Gudmundsson L. GRACE-REC: a reconstruction of climate-driven water storage changes over the last century[J]. Earth System Science Data, 2019, 11(3): 11531170 .

Jasechko S, Sharp ZD, Gibson JJ, Birks SJ, Yi Y, Fawcett PJ. Terrestrial water fluxes dominated by transpiration. Nature. 2013;496(7445):347-350.

Jensen L, Eicker A, Dobslaw H, et al. Long-term wetting and drying trends in land water storage derived from GRACE and CMIP5 models[J]. Journal of Geophysical Research: Atmospheres, 2019, 124(17-18): 9808-9823.

Koirala S, Jung M, Reichstein M, et al. Global distribution of groundwater-vegetation spatial covariation[J]. Geophysical Research Letters, 2017, 44(9): 4134-4142.

Kooperman GJ, Fowler MD, Hoffman FM, et al. Plant Physiological Responses to Rising CO 2 Modify Simulated Daily Runoff Intensity With Implications for GlobalScale Flood Risk Assessment. Geophysical Research Letters. 2018;45(22):12,45712,466 .

Lemordant L, Gentine P, Swann AS, Cook BI, Scheff J. Critical impact of vegetation physiology on the continental hydrologic cycle in response to increasing CO 2. Proceedings of the National Academy of Sciences. 2018;115(16):4093-4098.

Li Y, Piao S, Li LZX, et al. Divergent hydrological response to large-scale afforestation and vegetation greening in China. Science Advances. 2018;4(5)

Mankin J S, Seager R, Smerdon J E, et al. Mid-latitude freshwater availability reduced by projected vegetation responses to climate change[J]. Nature Geoscience, 2019, 12(12): 983-988.

Mankin JS, Seager R, Smerdon JE, Cook BI, Williams AP, Horton RM. Blue Water Trade-Offs With Vegetation in a CO 2 -Enriched Climate. Geophysical Research Letters. 2018;45(7):3115-3125. 
Ndehedehe C E, Ferreira V G, Onojeghuo A O, et al. Influence of global climate on freshwater changes in Africa's largest endorheic basin using multi-scaled indicators[J]. Science of The Total Environment, 2020: 139643.

Ni S, Chen J, Wilson C R, et al. Global terrestrial water storage changes and connections to ENSO events[J]. Surveys in Geophysics, 2018, 39(1): 1-22.

Rodell M, Famiglietti J S, Wiese D N, et al. Emerging trends in global freshwater availability[J]. Nature, 2018, 557(7707): 651-659.

Skinner CB, Poulsen CJ, Chadwick R, Diffenbaugh NS, Fiorella RP. The Role of Plant CO 2 Physiological Forcing in Shaping Future Daily-Scale Precipitation. Journal of Climate. 2017;30(7):2319-2340.

Skinner CB, Poulsen CJ, Mankin JS. Amplification of heat extremes by plant CO2 physiological forcing. Nature Communications. 2018;9(1).

Tao S, Zhang H, Feng Y, et al. Changes in China's water resources in the early $21 \mathrm{st}$ century[J]. Frontiers in Ecology and the Environment, 2020, 18(4): 188-193.

Tapley B D, Watkins M M, Flechtner F, et al. Contributions of GRACE to understanding climate change[J]. Nature climate change, 2019, 9(5): 358-369.

Thomas B F, Famiglietti J S. Identifying climate-induced groundwater depletion in GRACE observations[J]. Scientific reports, 2019, 9(1): 1-9.

Trancoso R, Larsen J R, McVicar T R, et al. CO2-vegetation feedbacks and other climate changes implicated in reducing base flow[J]. Geophysical Research Letters, 2017, 44(5): 2310-2318.

Ukkola AM, Prentice IC, Keenan TF, et al. Reduced streamflow in water-stressed climates consistent with $\mathrm{CO} 2$ effects on vegetation. Nature Climate Change. 2016;6(1):75-78.

Wang J, Song C, Reager $\mathrm{J}$ T, et al. Recent global decline in endorheic basin water storages[J]. Nature geoscience, 2018, 11(12): 926-932.

Wang X, Xiao X, Zou Z, et al. Gainers and losers of surface and terrestrial water resources in China during 1989-2016[J]. Nature communications, 2020, 11(1): 1-12.

Watkins M M, Wiese D N, Yuan D N, et al. Improved methods for observing Earth's time variable mass distribution with GRACE using spherical cap mascons[J]. Journal of Geophysical Research: Solid Earth, 2015, 120(4): 2648-2671. 
Wei X, Li Q, Zhang M, et al. Vegetation cover-another dominant factor in determining global water resources in forested regions $[\mathrm{J}]$. Global change biology, 2018, 24(2): 786-795.

Wiese D N, Landerer F W, Watkins M M. Quantifying and reducing leakage errors in the JPL RL05M GRACE mascon solution[J]. Water Resources Research, 2016, 52(9): 7490-7502.

Wu W Y, Lo M H, Wada Y, et al. Divergent effects of climate change on future groundwater availability in key mid-latitude aquifers[J]. Nature communications, 2020, 11(1): 1-9.

Xu L, Chen N, Zhang X, et al. Spatiotemporal changes in China's terrestrial water storage from GRACE satellites and its possible drivers[J]. Journal of Geophysical Research: Atmospheres, 2019, 124(22): 11976-11993.

Zeng Z, Peng L, Piao S. Response of terrestrial evapotranspiration to Earth's greening. Current Opinion in Environmental Sustainability. 2018a;33:9-25.

Zeng Z, Piao S, Li LZX, et al. Impact of Earth Greening on the Terrestrial Water Cycle. Journal of Climate. 2018b;31(7):2633-2650.

Zhang Y, He B, Guo L, et al. The relative contributions of precipitation, evapotranspiration, and runoff to terrestrial water storage changes across 168 river basins[J]. Journal of Hydrology, 2019, 579: 124194.

Zhu Z, Piao S, Myneni RB, et al. Greening of the Earth and its drivers. Nature Climate Change. 2016;6(8):791-795.

\section{Figure legends}

Fig 1. Spatial patterns of composite mean terrestrial water storage (GRACE) anomalies associated with the 5\% lowest (a) and 5\% highest (b) monthly LAI, (c),(d)same as figure (a),(b)., but of composite mean GRACE reconstruction (GRACE-REC) anomalies.

Fig 2. Time series of annual mean terrestrial water storage (GRACE) and LAI of 20022016 of demand-limited (a) and supply-limited (b) region, (c), (d)same as figure (a), (b)., but of GRACE reconstruction (GRACE-REC) time series of 1982-2016. 
Fig 3. Spatial distribution of sensitivity of TWS (GRACE) on LAI change computed for the 2002-2016 period (a), the zonal mean sensitivity latitude distribution(b), (c),(d)same as figure (a),(b)., but of GRACE reconstruction (GRACE-REC) computed for the 1982-2016 period.

Fig 4. Sensitivity of TWS (GRACE) on LAI change computed for the 2002-2016 period binned as a function of climatological mean Precipitation and Temperature (a), (b) same as (a)., but of GRACE reconstruction (GRACE-REC) computed for the 19822016 period.

Fig 5. Temporal variations in $\partial \mathrm{TWS} / \partial \mathrm{LAI}$ (Sensitivity of GRACE-REC on LAI change) computed over a 7-year moving window for moisture supply-limited and atmospheric demand-limited regions, and the whole globe(a), (b) same as (a)., but of 12-year moving window.

Fig 6. Spatial pattern of TWS (GRACE-REC) trend computed for the 1982-2016 period (a), and spatial pattern of LAI-related TWS (GRACE-REC) trend computed of TWS trend associated with long-term trends in LAI (b).

Fig 7. LAI-related TWS trend binned as a function of climatological mean $\mathrm{P}$ and $\mathrm{T}$ (a), the latitude distribution of zonal mean LAI-related TWS trend (blue) and original TWS trend (black) (b), all TWS are using GRACE-REC data.

Fig 8. Effects of the long-term trends in LAI, T, P on the TWS (GRACE-REC) trend (a), sensitivity of TWS (GRACE-REC) on LAI (b), LAI-related TWS (GRACE-REC) trend (c), all computed for moisture supply-limited and atmospheric demand-limited regions and the whole globe. The spatial domains of supply-limited and demand-limited regions are shown in Supplementary Fig. 2. 
Fig 9. Effects of the long-term trends in LAI, T, P on the TWS (GRACE-REC) trend (a), sensitivity of TWS (GRACE-REC) on LAI (b), P (c), T (d), all of 6 land cover classes: tropical forest, extra-tropical forest, semi-arid ecosystems, tundra and arctic shrub land, grasslands and crops, and sparsely vegetated.

Fig 10. Temporal variations in TWS (GRACE-REC), LAI-related TWS (LAIreconstructed TWS) computed for the 1982-2016 period for semi-arid (a), grasslands crops (b), and sparsely vegetated (c) regions.

Fig 11. Map of 6 land cover classes: tropical forest, extra-tropical forest, semi-arid ecosystems, tundra and arctic shrub land, grasslands and crops, and sparsely vegetated. 

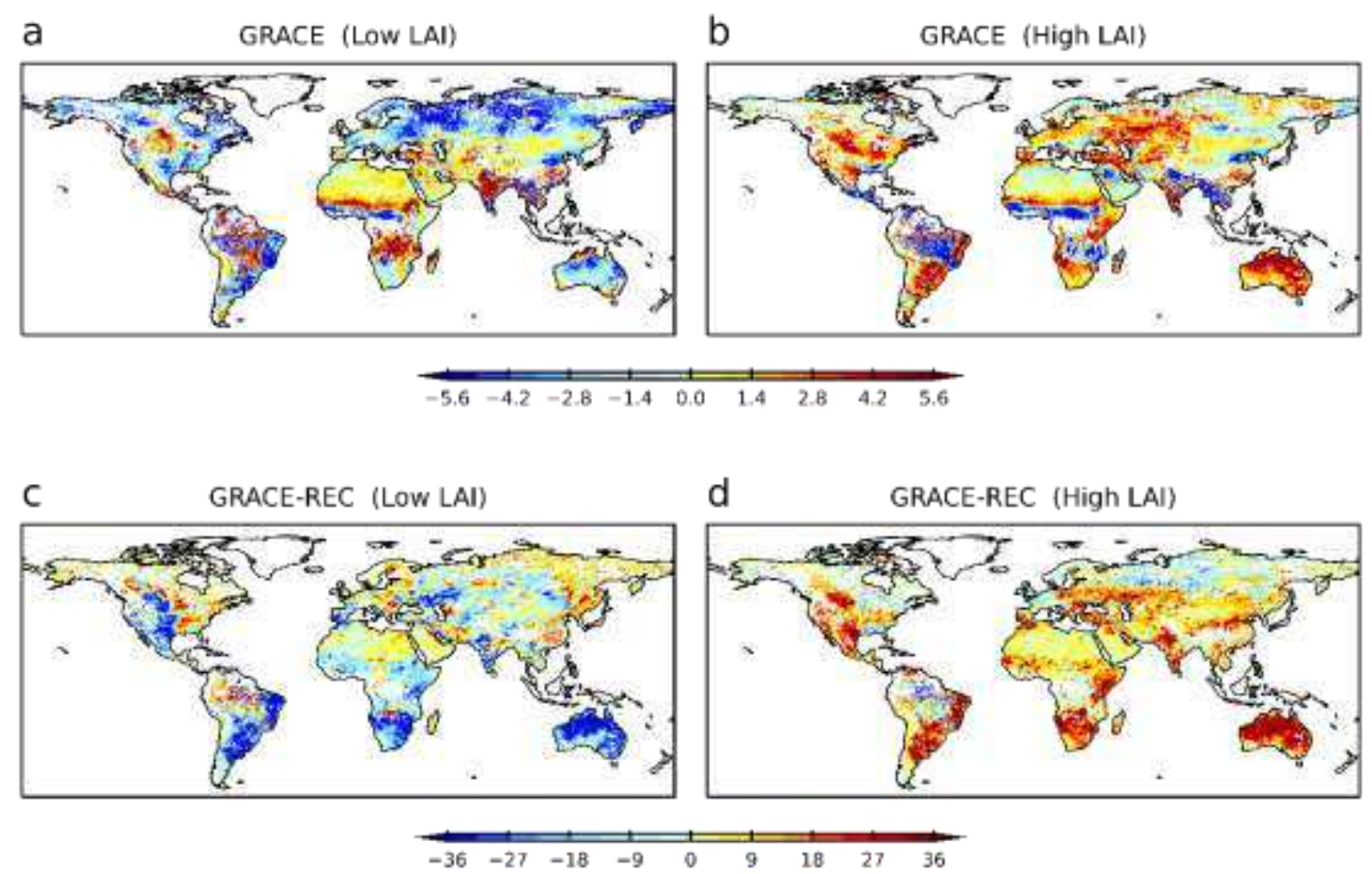

Fig 1. Spatial patterns of composite mean terrestrial water storage (GRACE) anomalies associated with the 5\% lowest (a) and 5\% highest (b) monthly LAI, (c), (d)same as figure (a), (b)., but of composite mean GRACE reconstruction (GRACE-REC) anomalies. 

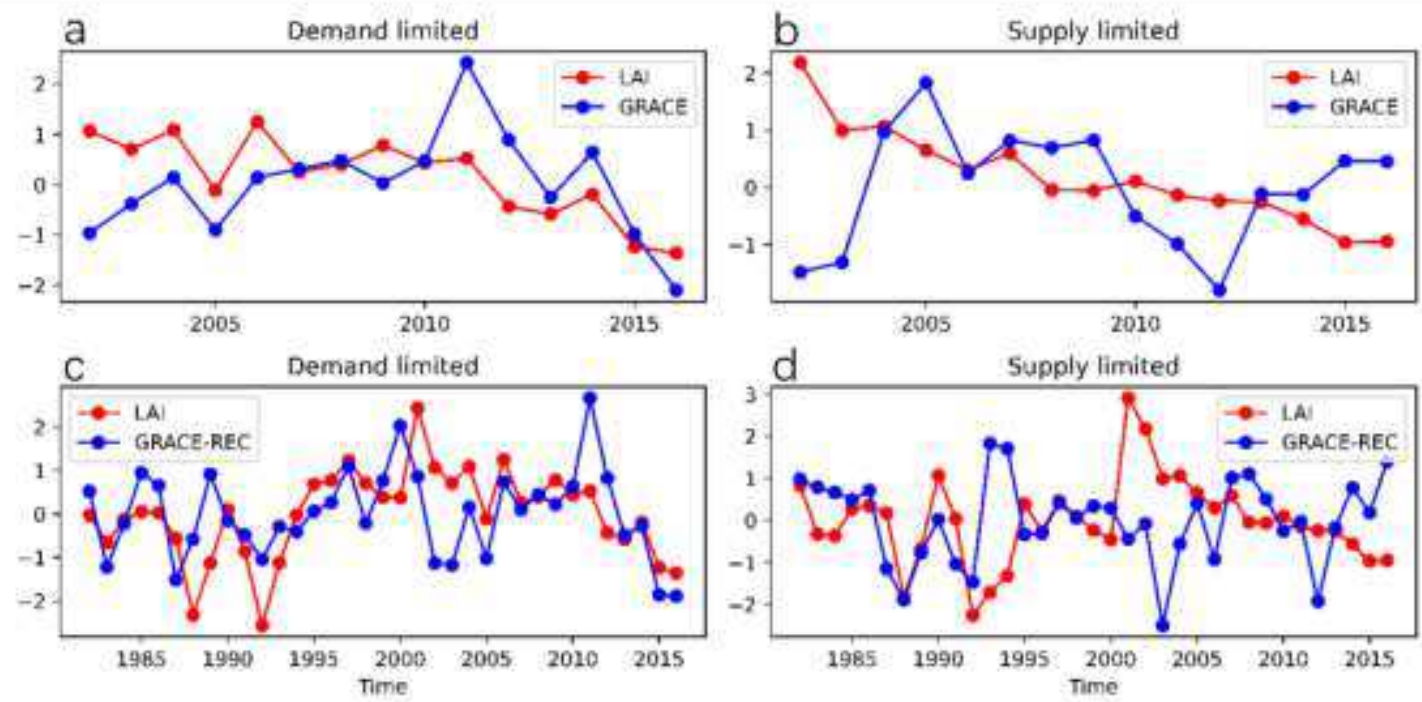

Fig 2. Time series of annual mean terrestrial water storage (GRACE) and LAI of 20022016 of demand-limited (a) and supply-limited (b) region, (c), (d)same as figure (a), (b)., but of GRACE reconstruction (GRACE-REC) time series of 1982-2016. 

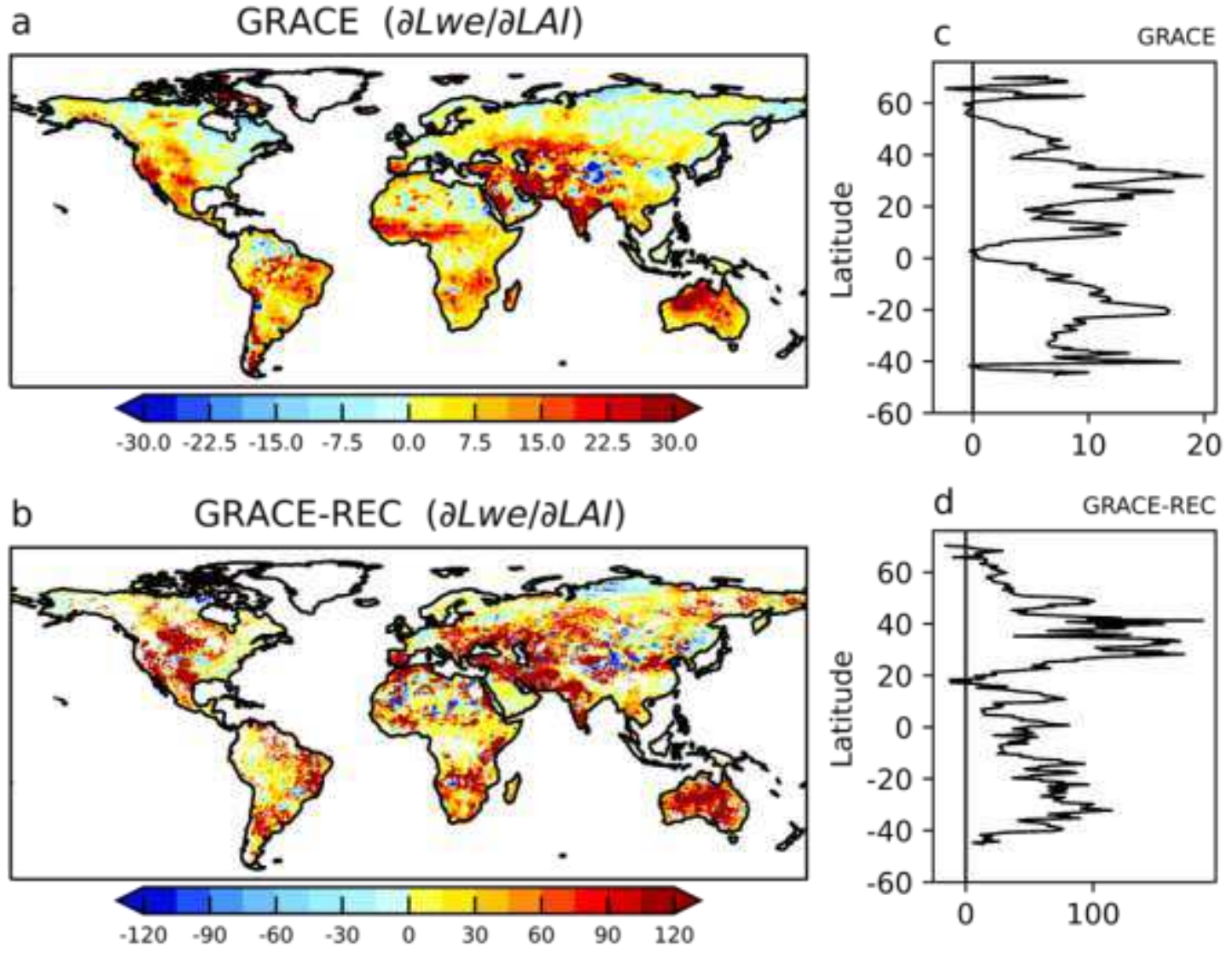

Fig 3. Spatial distribution of sensitivity of TWS (GRACE) on LAI change computed for the 2002-2016 period (a), the zonal mean sensitivity latitude distribution(b), (c), (d)same as figure (a), (b)., but of GRACE reconstruction (GRACE-REC) computed for the 1982-2016 period. 

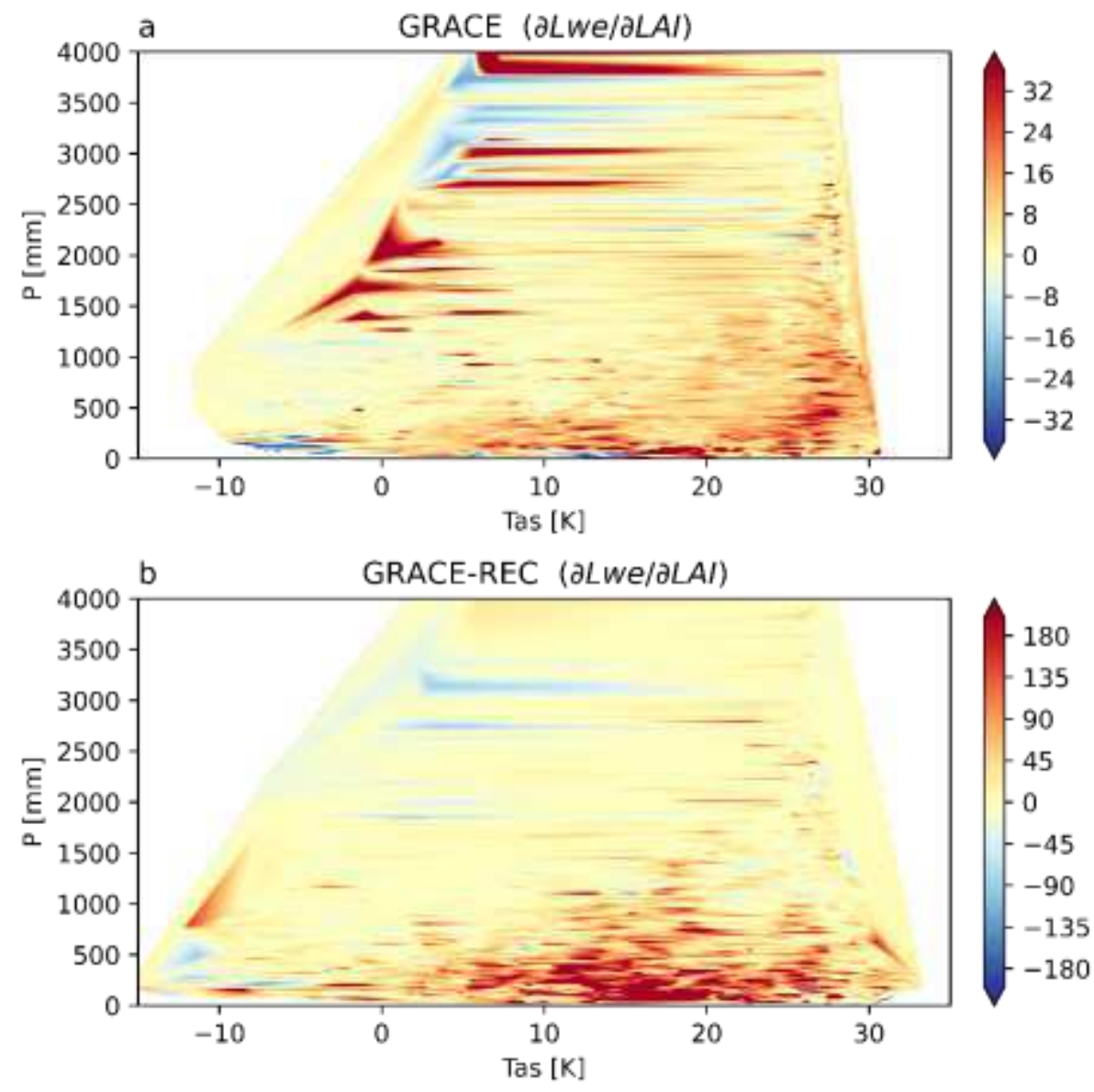

Fig 4. Sensitivity of TWS (GRACE) on LAI change computed for the 2002-2016 period binned as a function of climatological mean Precipitation and Temperature (a), (b) same as (a)., but of GRACE reconstruction (GRACE-REC) computed for the 19822016 period. 


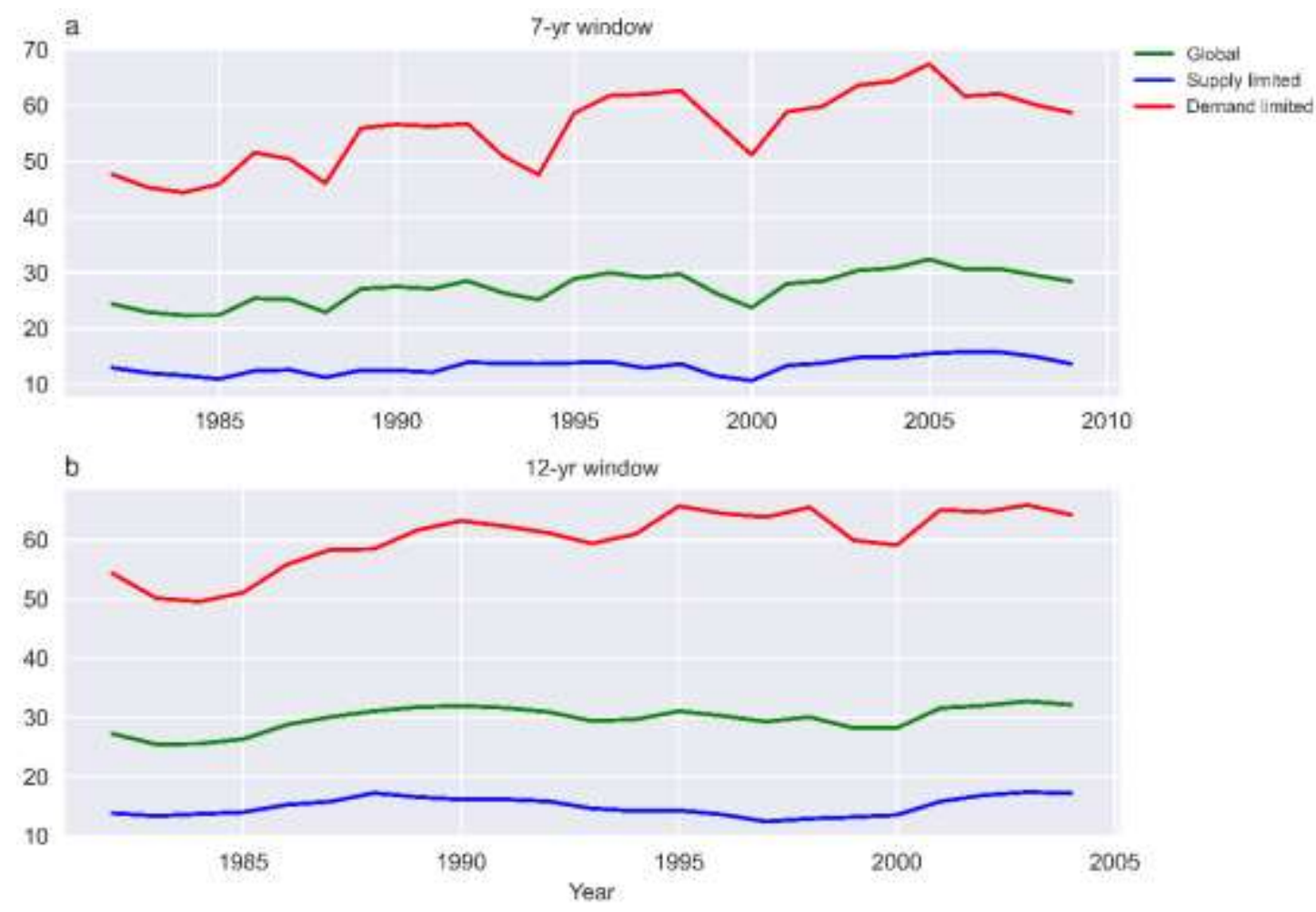

Fig 5. Temporal variations in $\partial \mathrm{TWS} / \partial \mathrm{LAI}$ (Sensitivity of GRACE-REC on LAI change) computed over a 7-year moving window for moisture supply-limited and atmospheric demand-limited regions, and the whole globe(a), (b) same as (a)., but of 12-year moving window. 

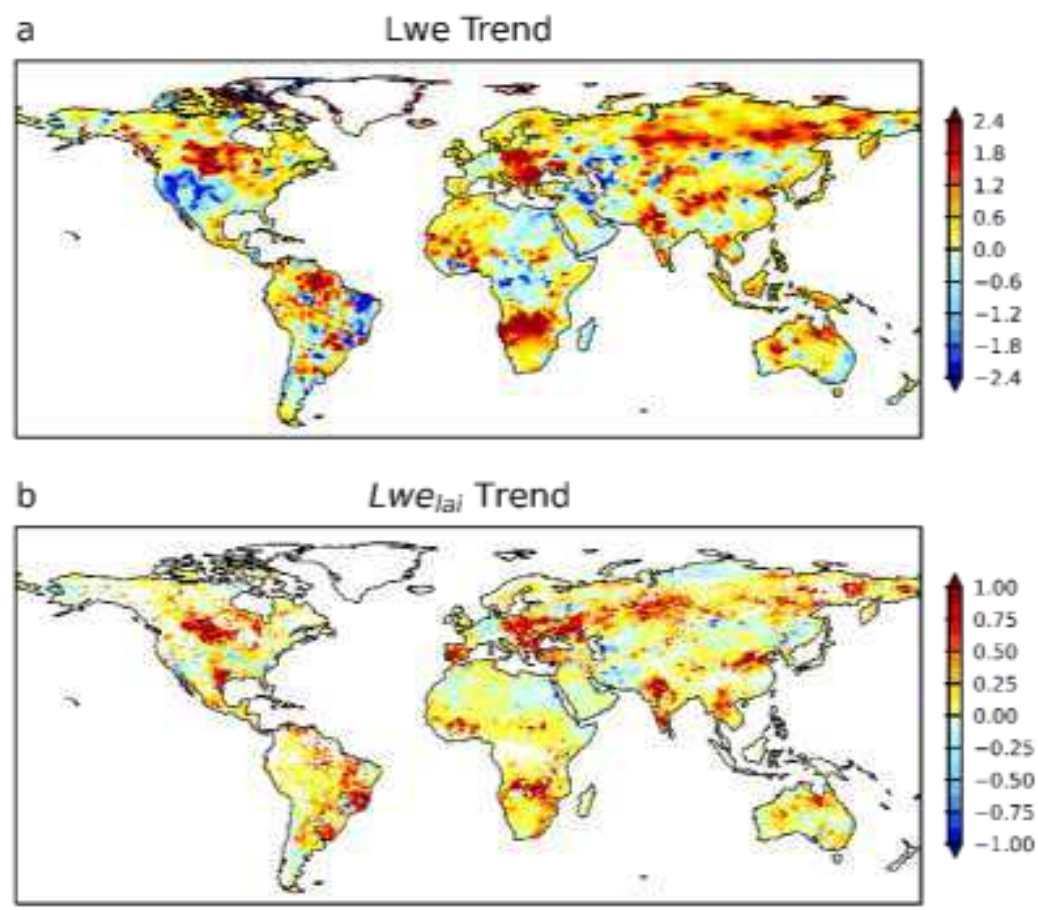

Fig 6. Spatial pattern of TWS (GRACE-REC) trend computed for the 1982-2016 period (a), and spatial pattern of LAI-related TWS (GRACE-REC) trend computed of TWS trend associated with long-term trends in LAI (b). 

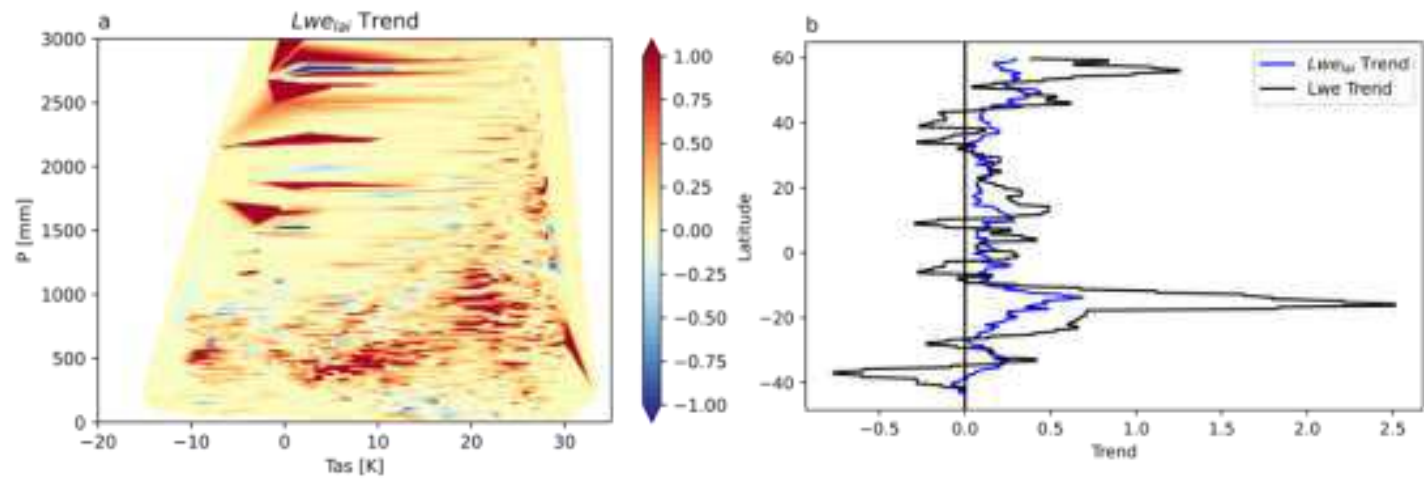

Fig 7. LAI-related TWS trend binned as a function of climatological mean P and T (a), the latitude distribution of zonal mean LAI-related TWS trend (blue) and original TWS trend (black) (b), all TWS are using GRACE-REC data. 

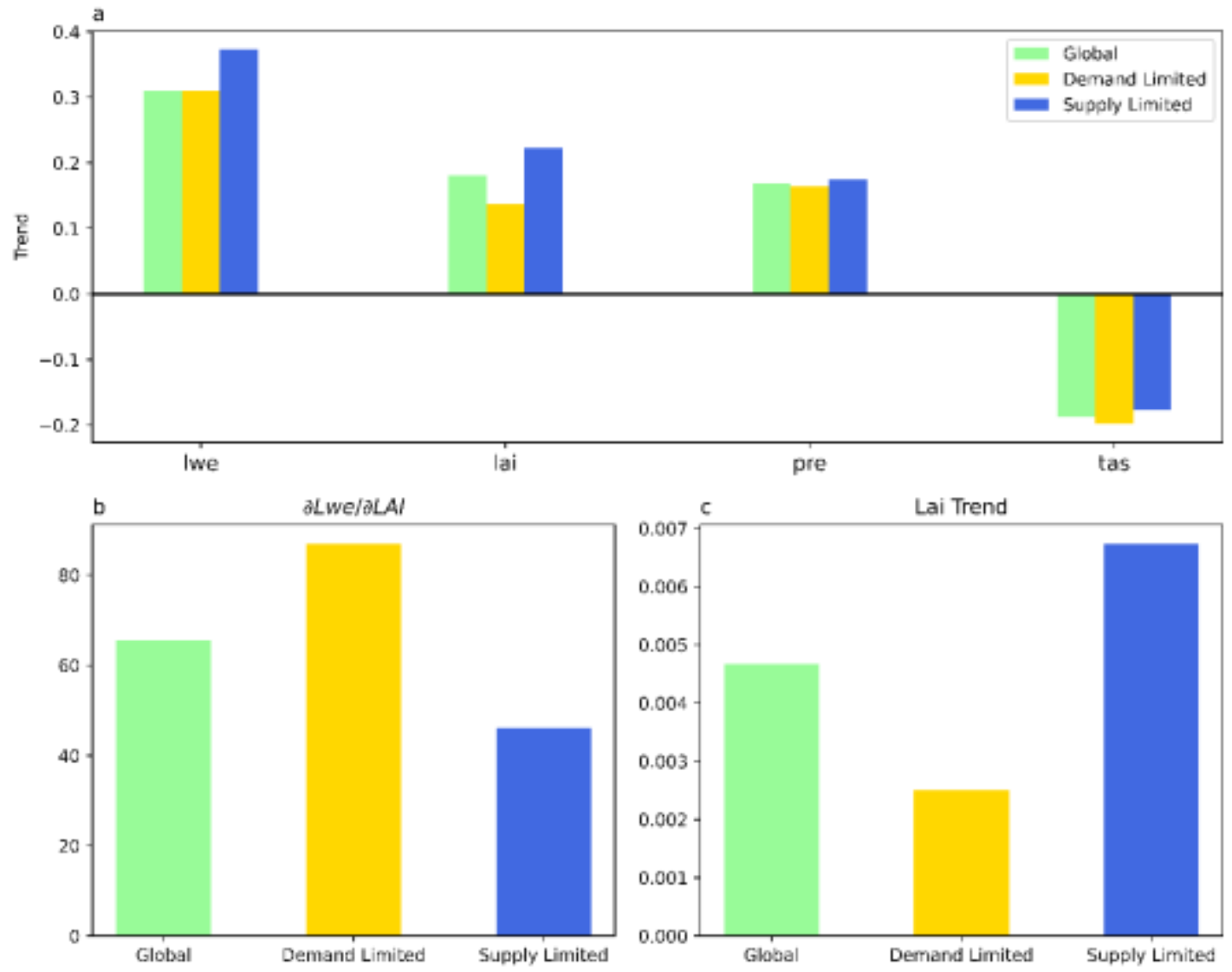

Fig 8. Effects of the long-term trends in LAI, T, P on the TWS (GRACE-REC) trend (a), sensitivity of TWS (GRACE-REC) on LAI (b), LAI-related TWS (GRACE-REC) trend (c), all computed for moisture supply-limited and atmospheric demand-limited regions and the whole globe. The spatial domains of supply-limited and demand-limited regions are shown in Supplementary Fig. 2. 

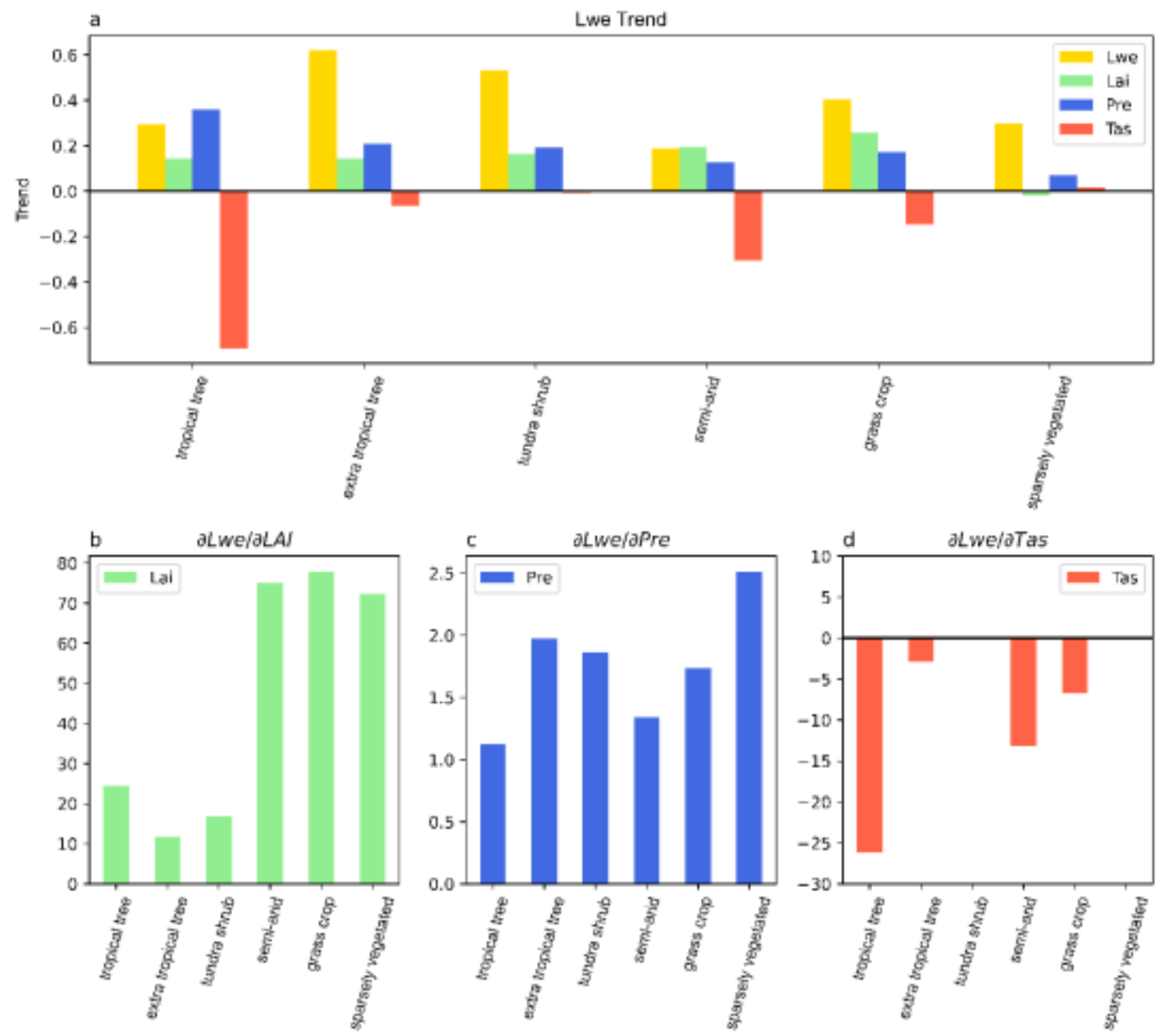

Fig 9. Effects of the long-term trends in LAI, T, P on the TWS (GRACE-REC) trend (a), sensitivity of TWS (GRACE-REC) on LAI (b), P (c), T (d), all of 6 land cover classes: tropical forest, extra-tropical forest, semi-arid ecosystems, tundra and arctic shrub land, grasslands and crops, and sparsely vegetated. 

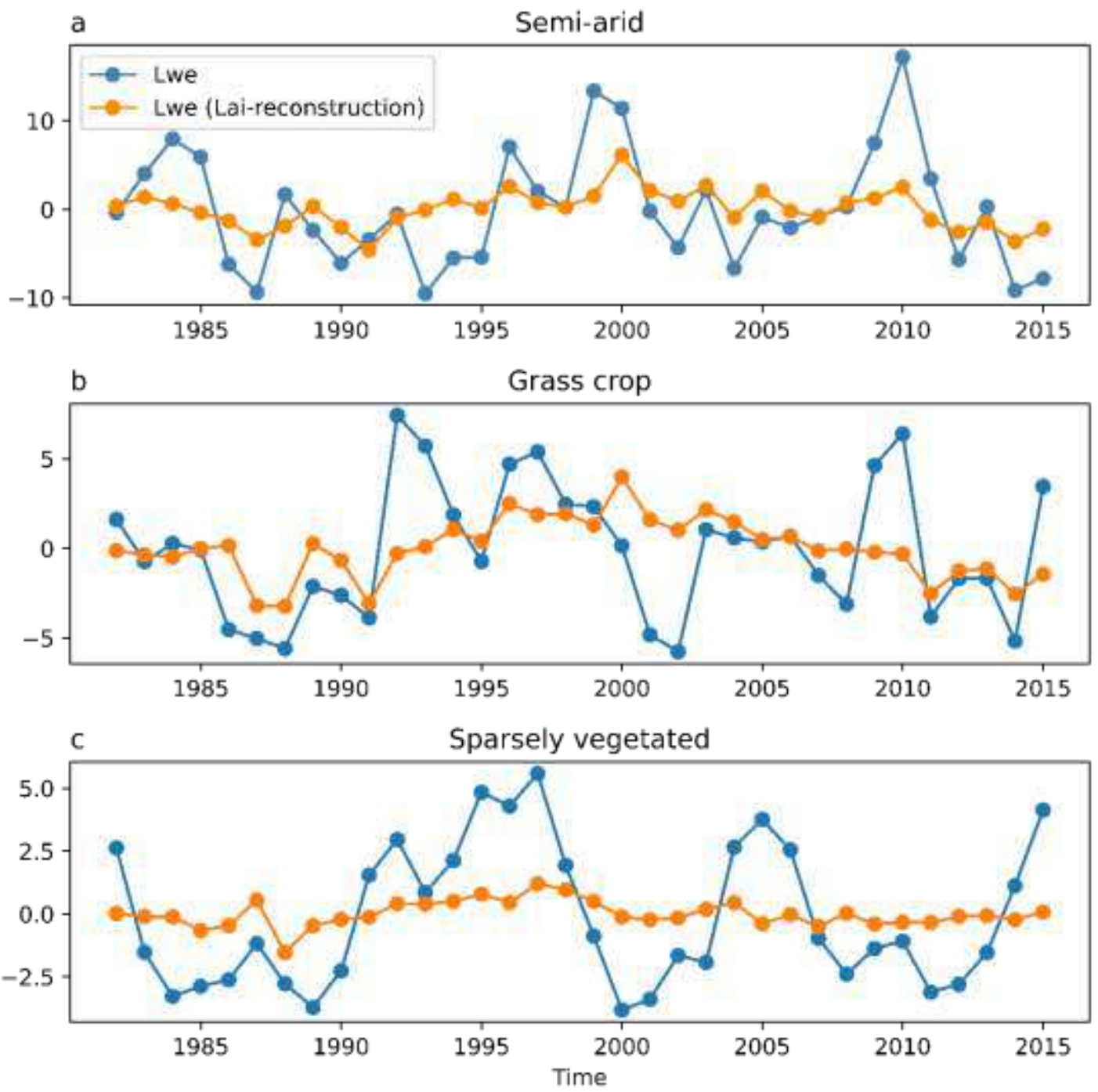

Fig 10. Temporal variations in TWS (GRACE-REC), LAI-related TWS (LAIreconstructed TWS) computed for the 1982-2016 period for semi-arid (a), grasslands crops (b), and sparsely vegetated (c) regions. 


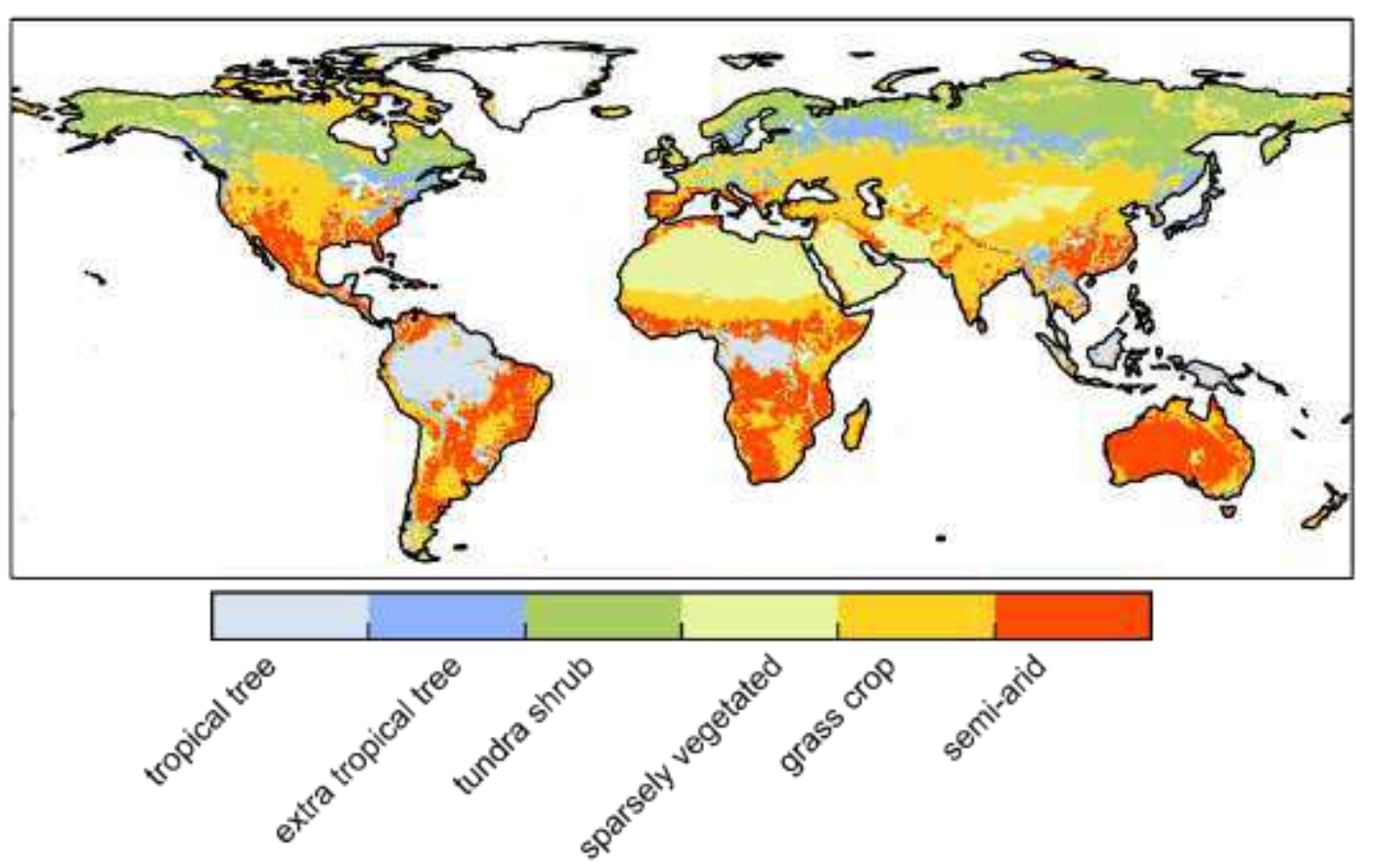

Fig 11. Map of 6 land cover classes: tropical forest, extra-tropical forest, semi-arid ecosystems, tundra and arctic shrub land, grasslands and crops, and sparsely vegetated. 
a

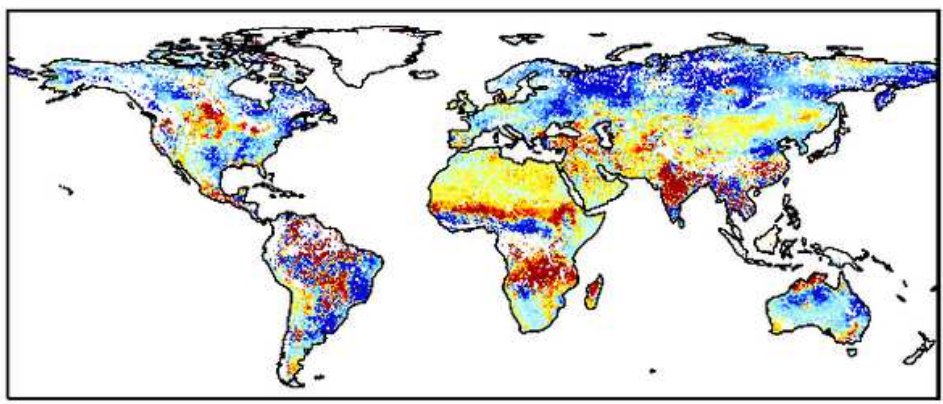

b

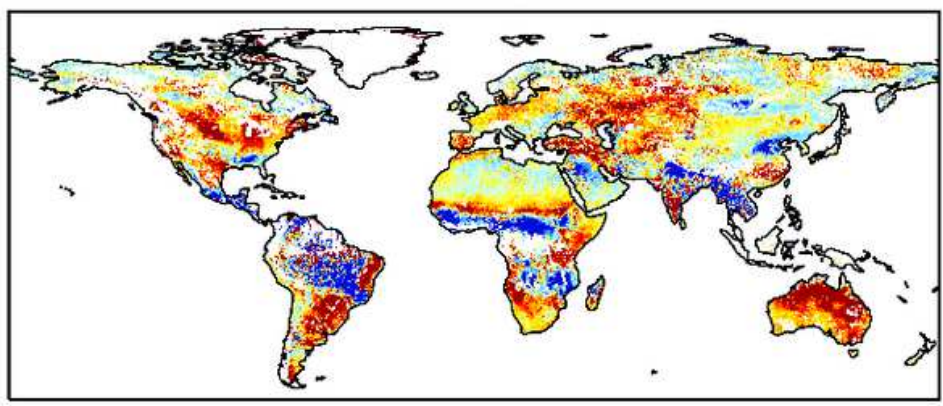

\begin{tabular}{lllllllll}
\hline-5.6 & -4.2 & -2.8 & -1.4 & 0.0 & 1.4 & 2.8 & 4.2 & 5.6
\end{tabular}

C

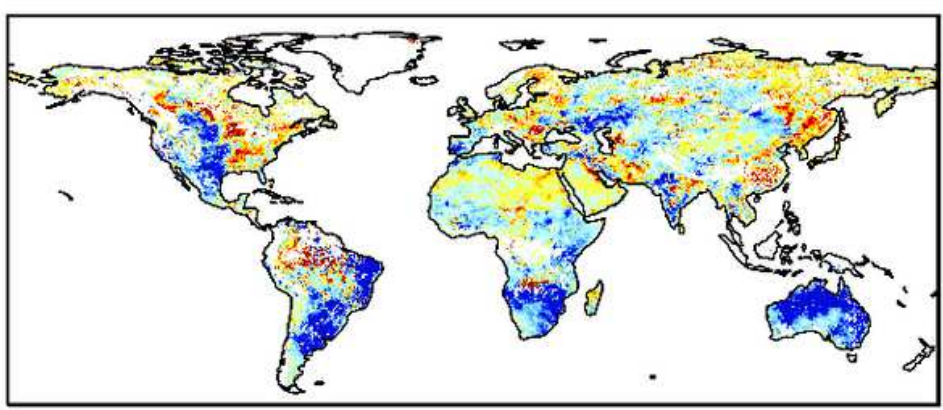

d GRACE-REC (High LAl)

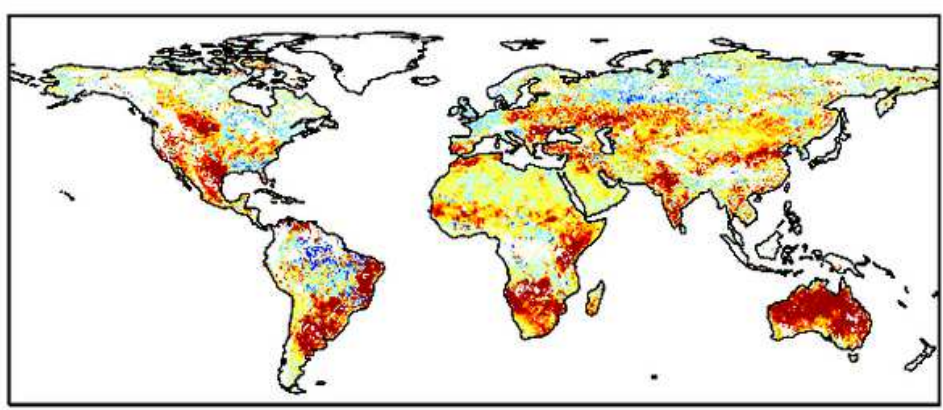

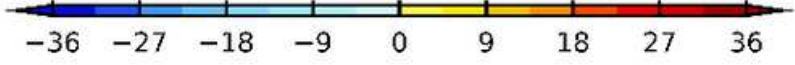

Figure 1

Spatial patterns of composite mean terrestrial water storage (GRACE) anomalies associated with the 5\% lowest (a) and $5 \%$ highest (b) monthly LAl, (c),(d)same as figure (a),(b)., but of composite mean GRACE reconstruction (GRACE-REC) anomalies. Note: The designations employed and the presentation of the material on this map do not imply the expression of any opinion whatsoever on the part of Research Square concerning the legal status of any country, territory, city or area or of its authorities, or concerning the delimitation of its frontiers or boundaries. This map has been provided by the authors. 

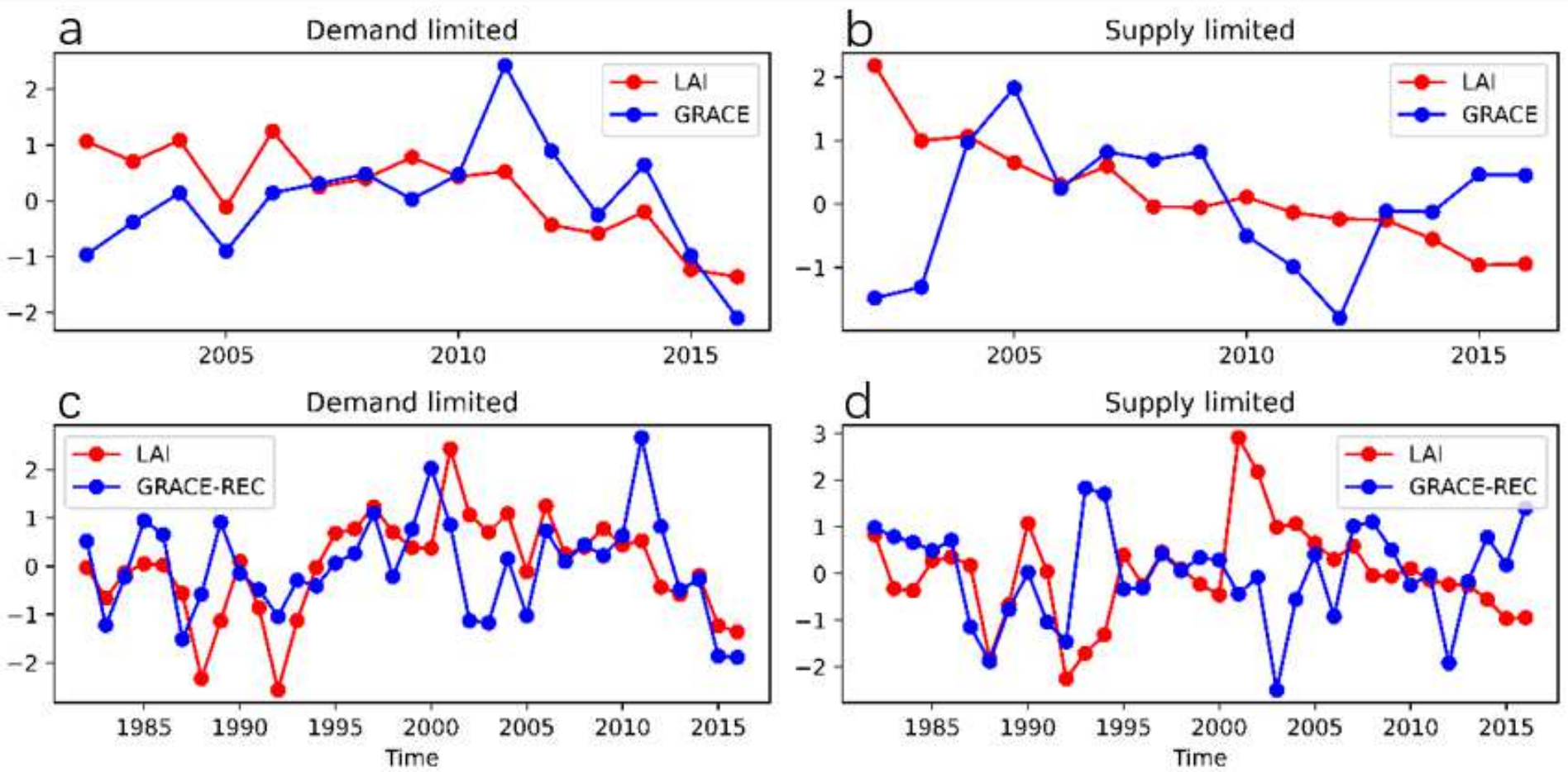

Figure 2

Time series of annual mean terrestrial water storage (GRACE) and LAl of 2002-2016 of demand-limited (a) and supply-limited (b) region, (c), (d)same as figure (a), (b)., but of GRACE reconstruction (GRACEREC) time series of 1982-2016. 
a

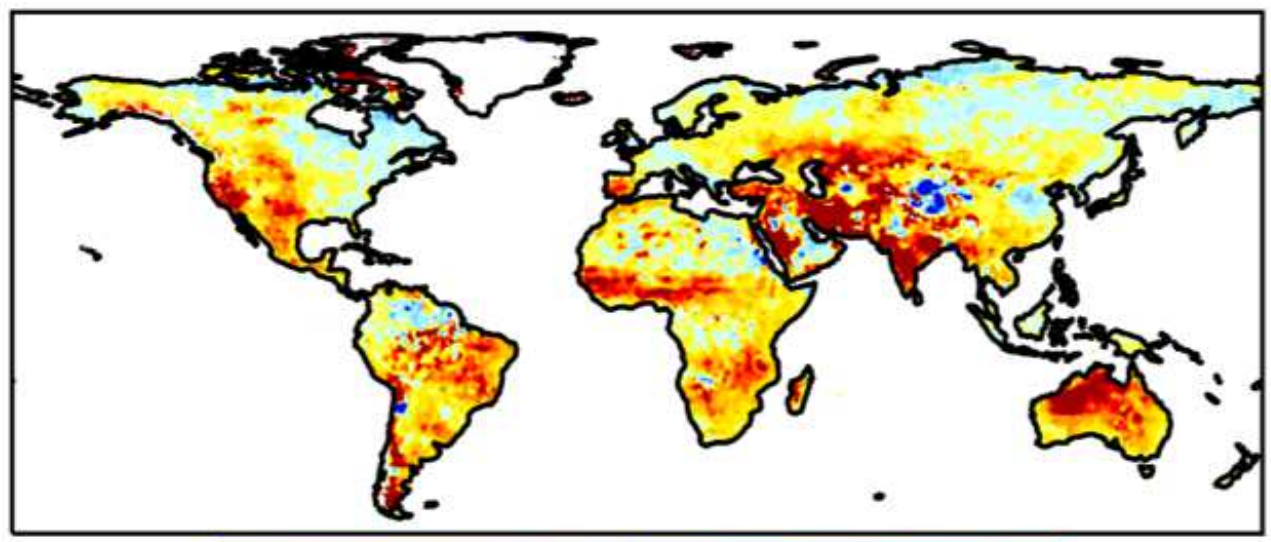

\begin{tabular}{ccccccccc}
\hline & $\mid$ & $\mid$ & $\mid$ & $\mid$ & $\mid$ & $\mid$ & | \\
\hline-30.0 & -22.5 & -15.0 & -7.5 & 0.0 & 7.5 & 15.0 & 22.5 & 30.0
\end{tabular}

b GRACE-REC ( $\partial L w e / \partial L A I)$

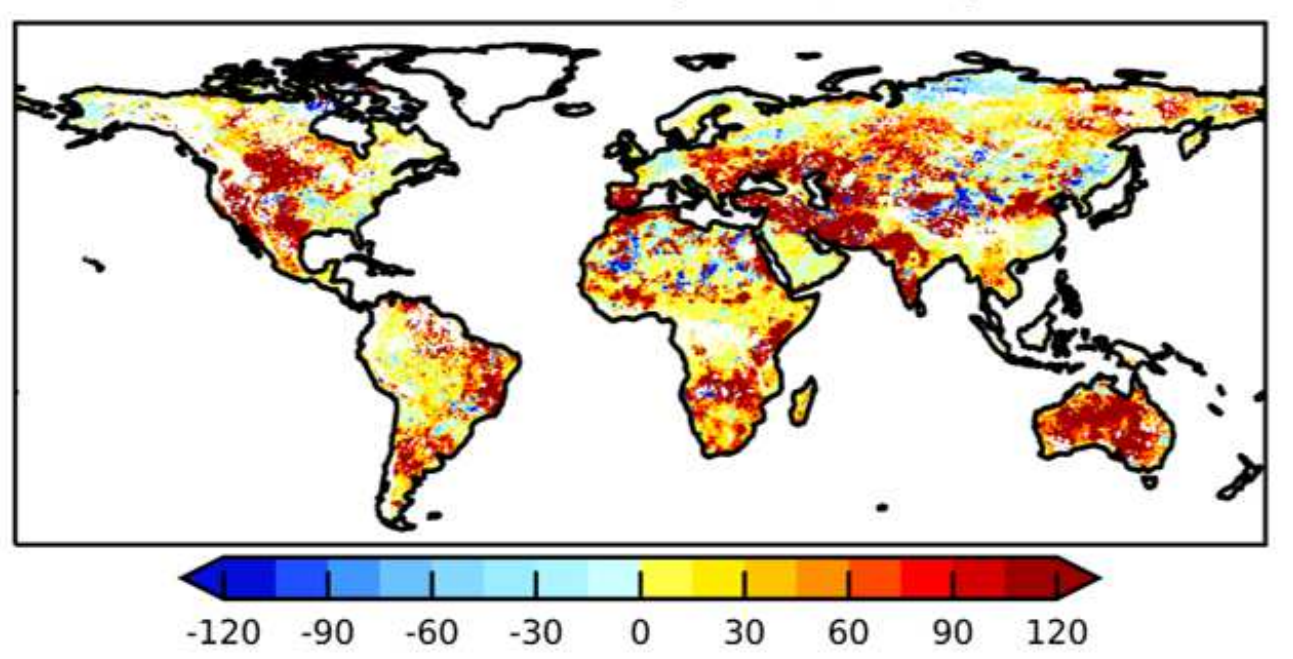

C

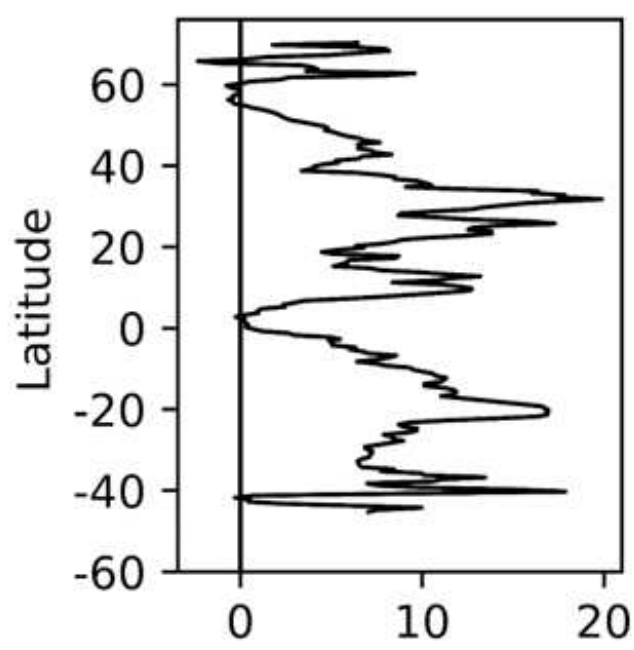

d

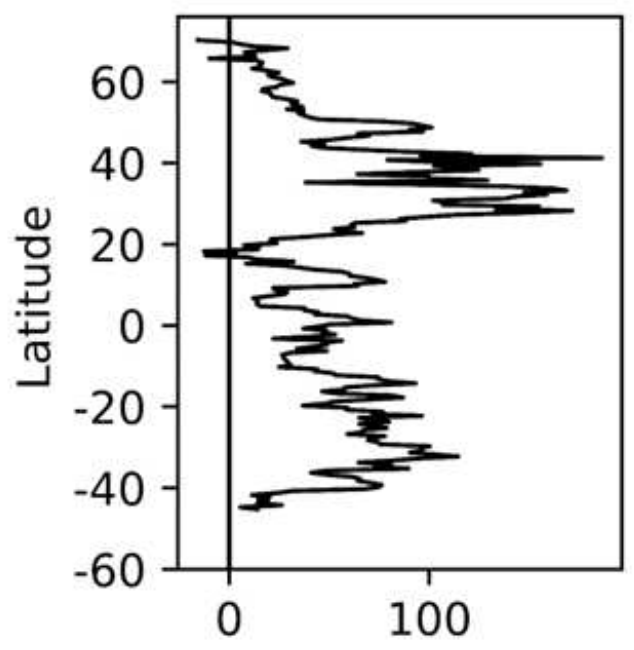

Figure 3

Spatial distribution of sensitivity of TWS (GRACE) on LAl change computed for the 2002-2016 period (a), the zonal mean sensitivity latitude distribution(b), (c),(d)same as figure (a),(b)., but of GRACE reconstruction (GRACE-REC) computed for the 1982-2016 period. Note: The designations employed and the presentation of the material on this map do not imply the expression of any opinion whatsoever on the part of Research Square concerning the legal status of any country, territory, city or area or of its authorities, or concerning the delimitation of its frontiers or boundaries. This map has been provided by the authors. 

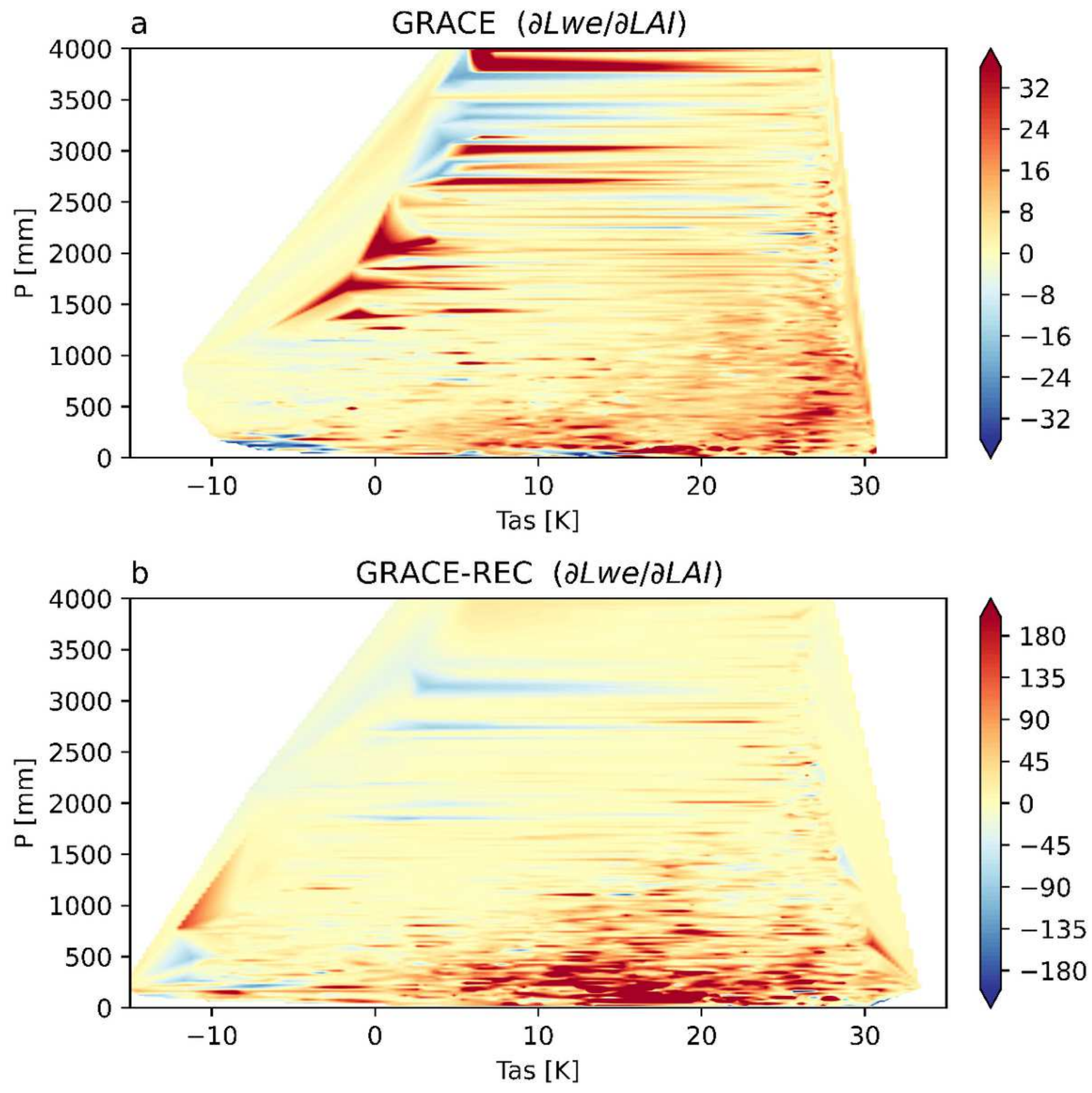

Figure 4

Sensitivity of TWS (GRACE) on LAl change computed for the 2002-2016 period binned as a function of climatological mean Precipitation and Temperature (a), (b) same as (a)., but of GRACE reconstruction (GRACE-REC) computed for the 1982-2016 period. 


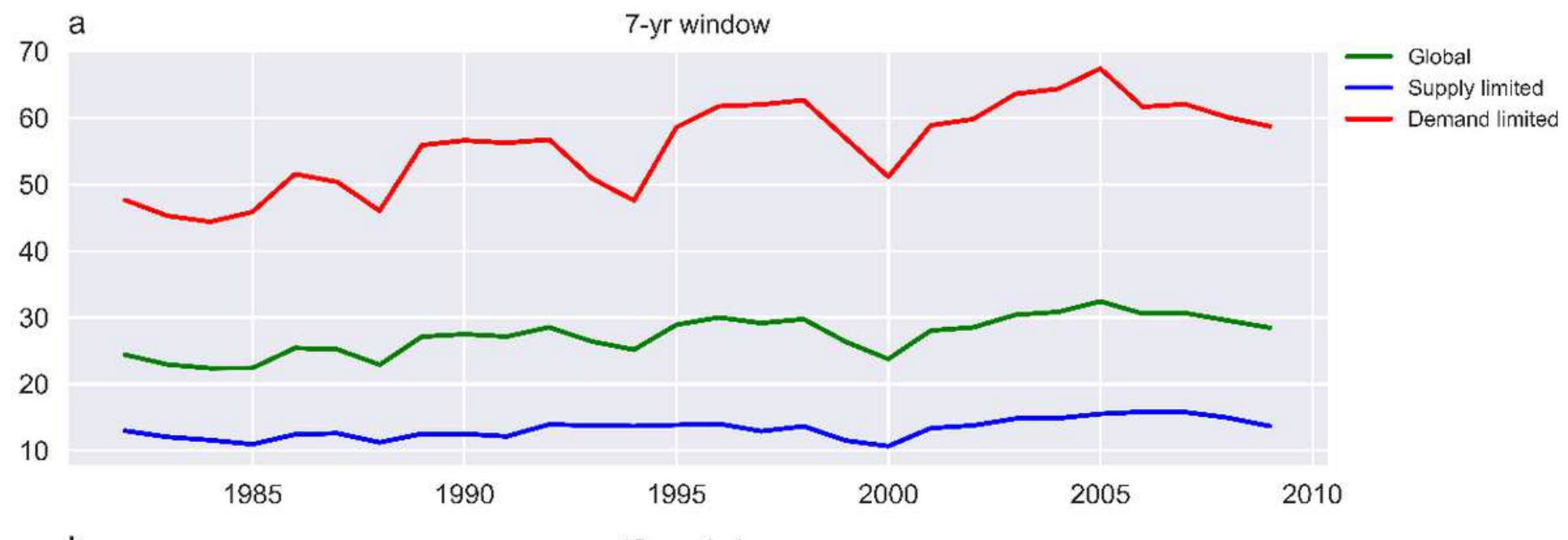

b

12-yr window

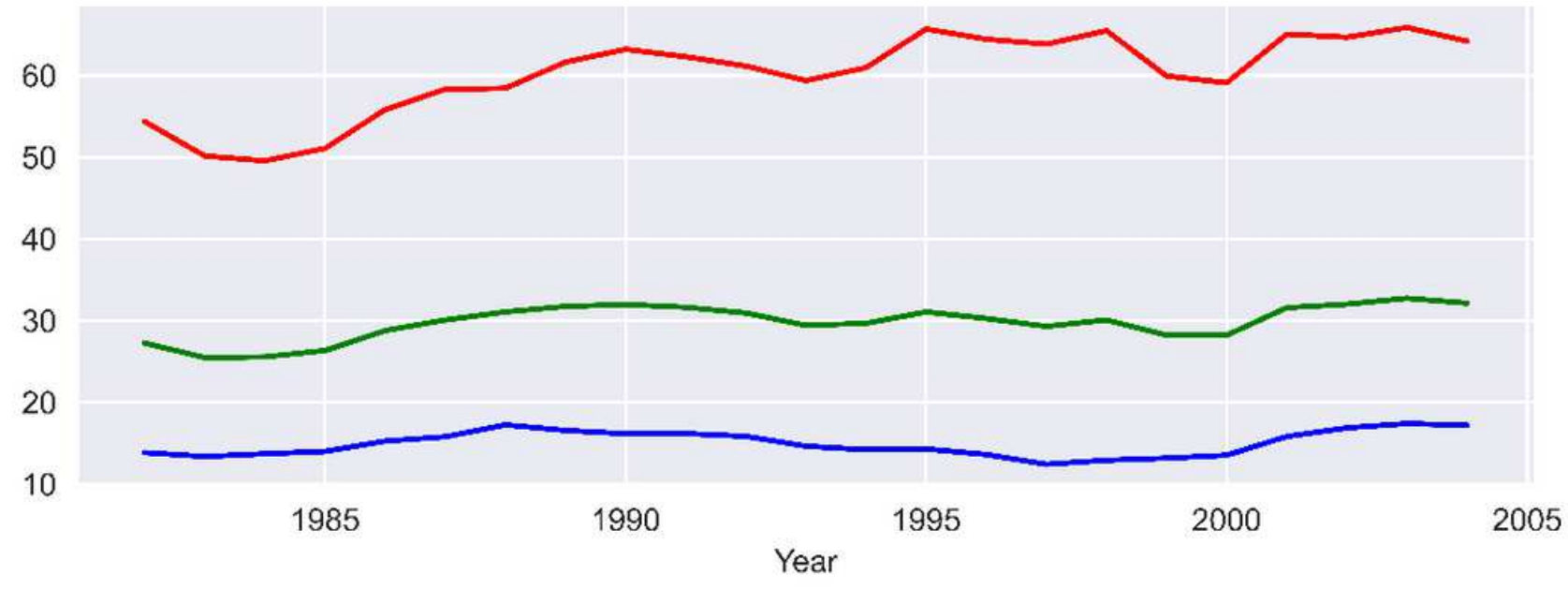

Figure 5

Temporal variations in $\partial$ TWS/DLAI (Sensitivity of GRACE-REC on LAl change) computed over a 7-year moving window for moisture supply-limited and atmospheric demand-limited regions, and the whole globe(a), (b) same as (a)., but of 12-year moving window. 

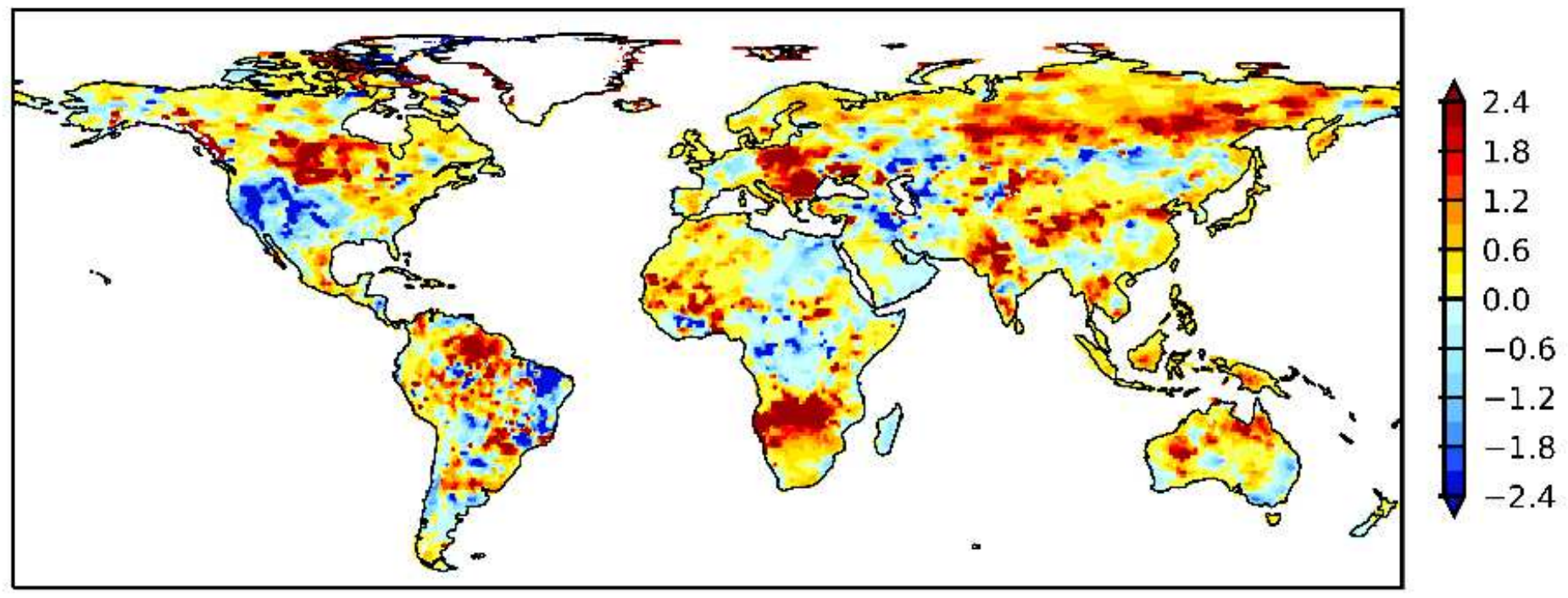

\section{b Lwe $\quad$ Lwi Trend}

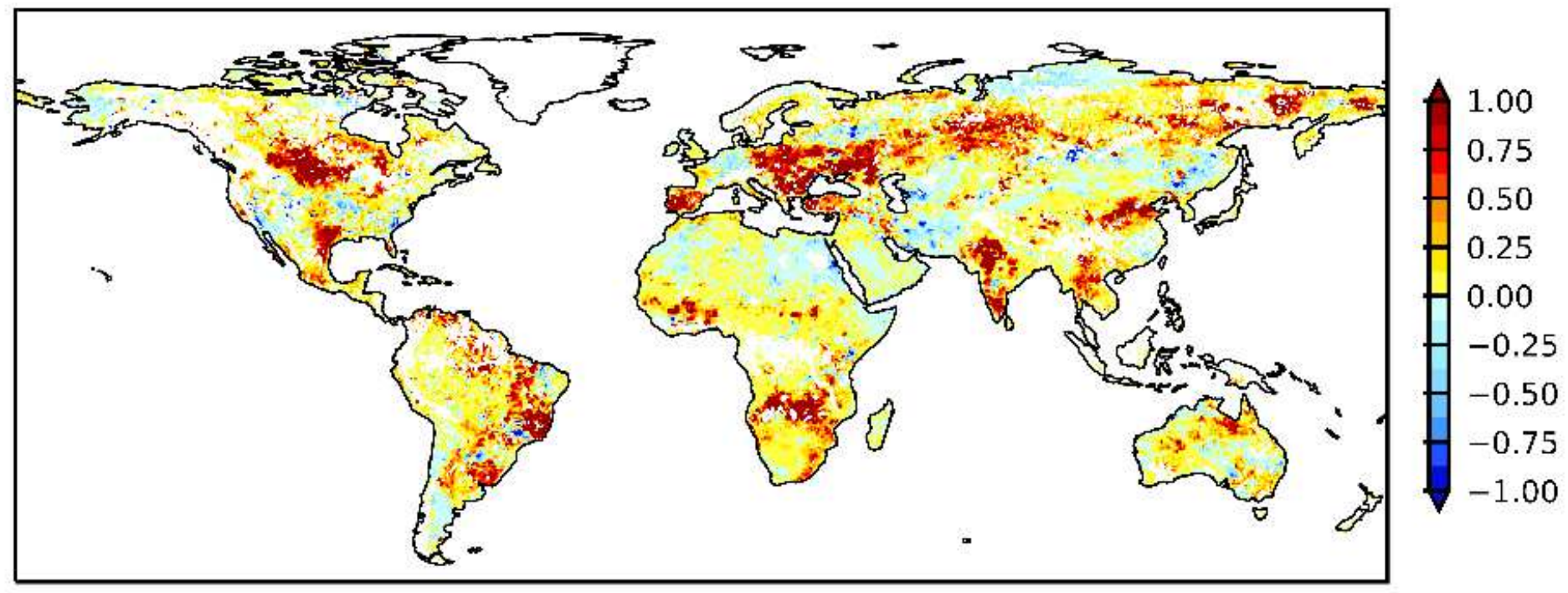

Figure 6

Spatial pattern of TWS (GRACE-REC) trend computed for the 1982-2016 period (a), and spatial pattern of LAl-related TWS (GRACE-REC) trend computed of TWS trend associated with long-term trends in LAI (b). Note: The designations employed and the presentation of the material on this map do not imply the expression of any opinion whatsoever on the part of Research Square concerning the legal status of any country, territory, city or area or of its authorities, or concerning the delimitation of its frontiers or boundaries. This map has been provided by the authors. 

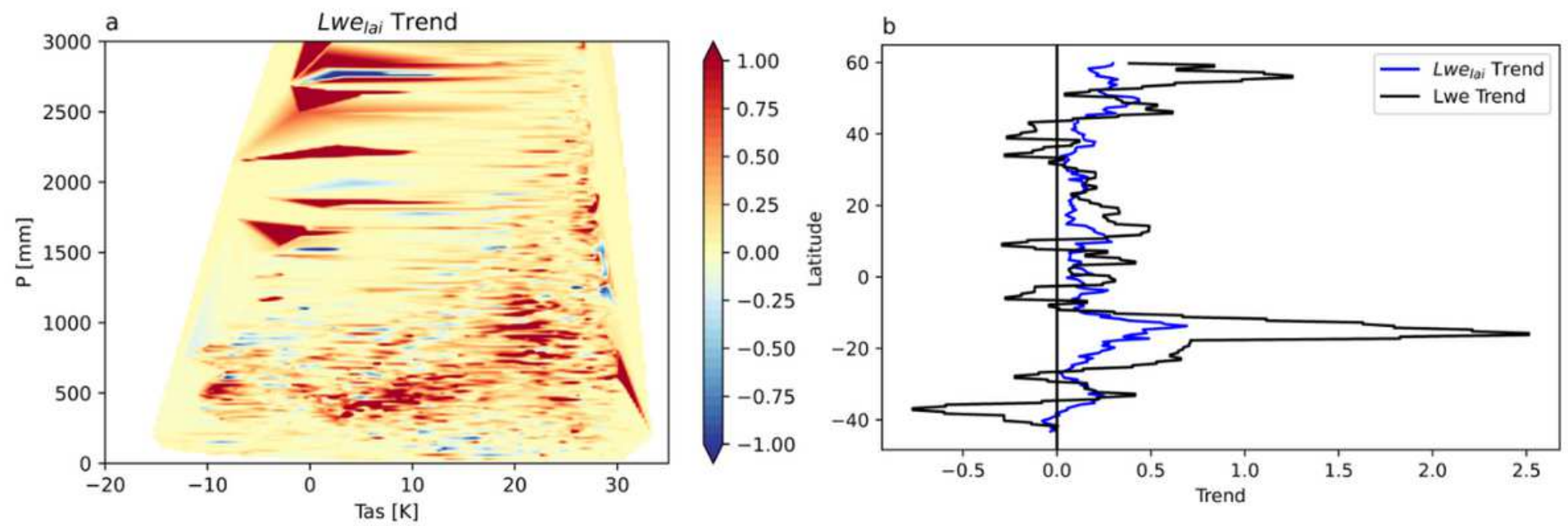

\section{Figure 7}

LAl-related TWS trend binned as a function of climatological mean P and T (a), the latitude distribution of zonal mean LAl-related TWS trend (blue) and original TWS trend (black) (b), all TWS are using GRACEREC data. 

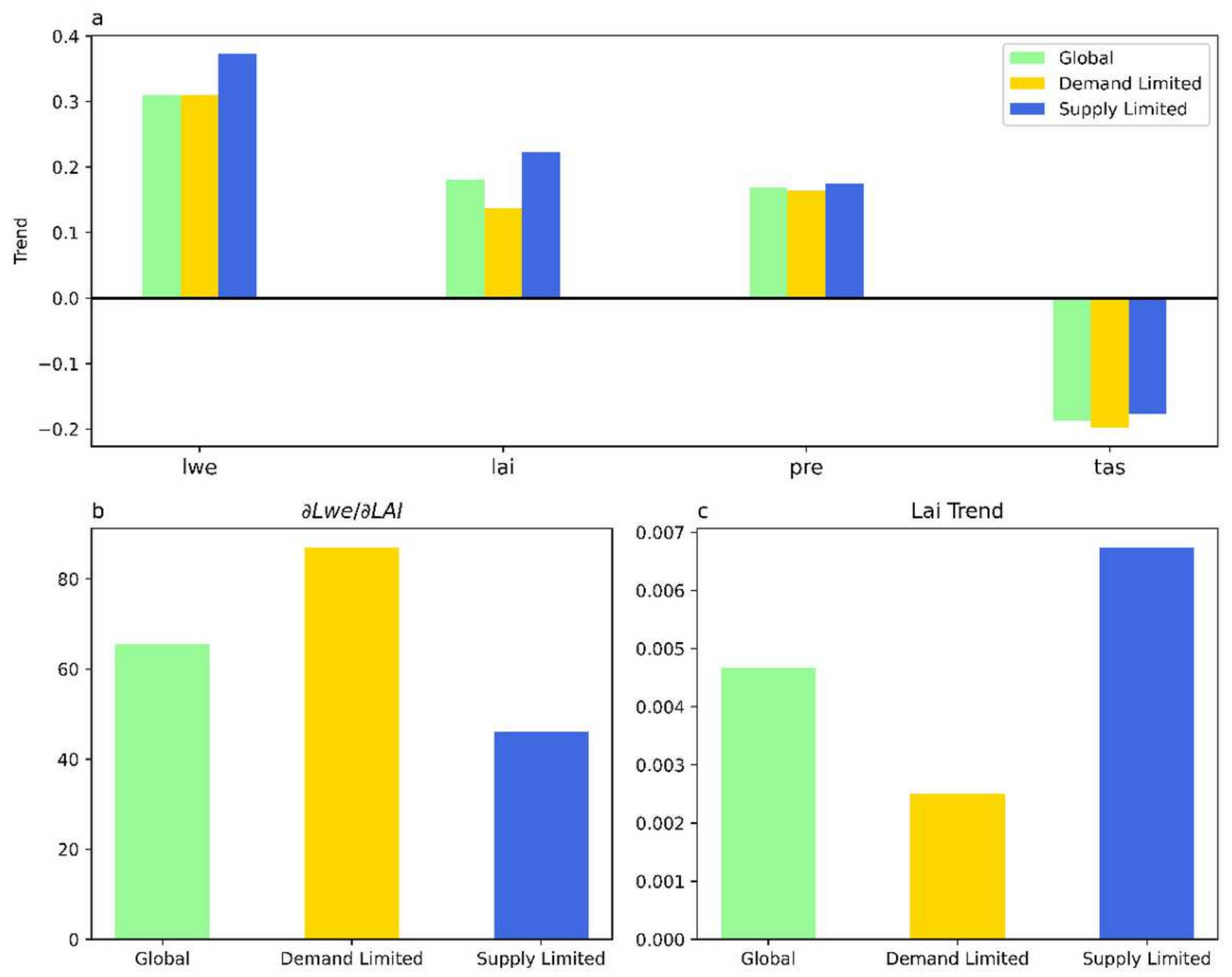

Figure 8

Effects of the long-term trends in LAI, T, P on the TWS (GRACE-REC) trend (a), sensitivity of TWS (GRACEREC) on LAI (b), LAl-related TWS (GRACE-REC) trend (c), all computed for moisture supply-limited and atmospheric demand-limited regions and the whole globe. The spatial domains of supply-limited and demand-limited regions are shown in Supplementary Fig. 2. 

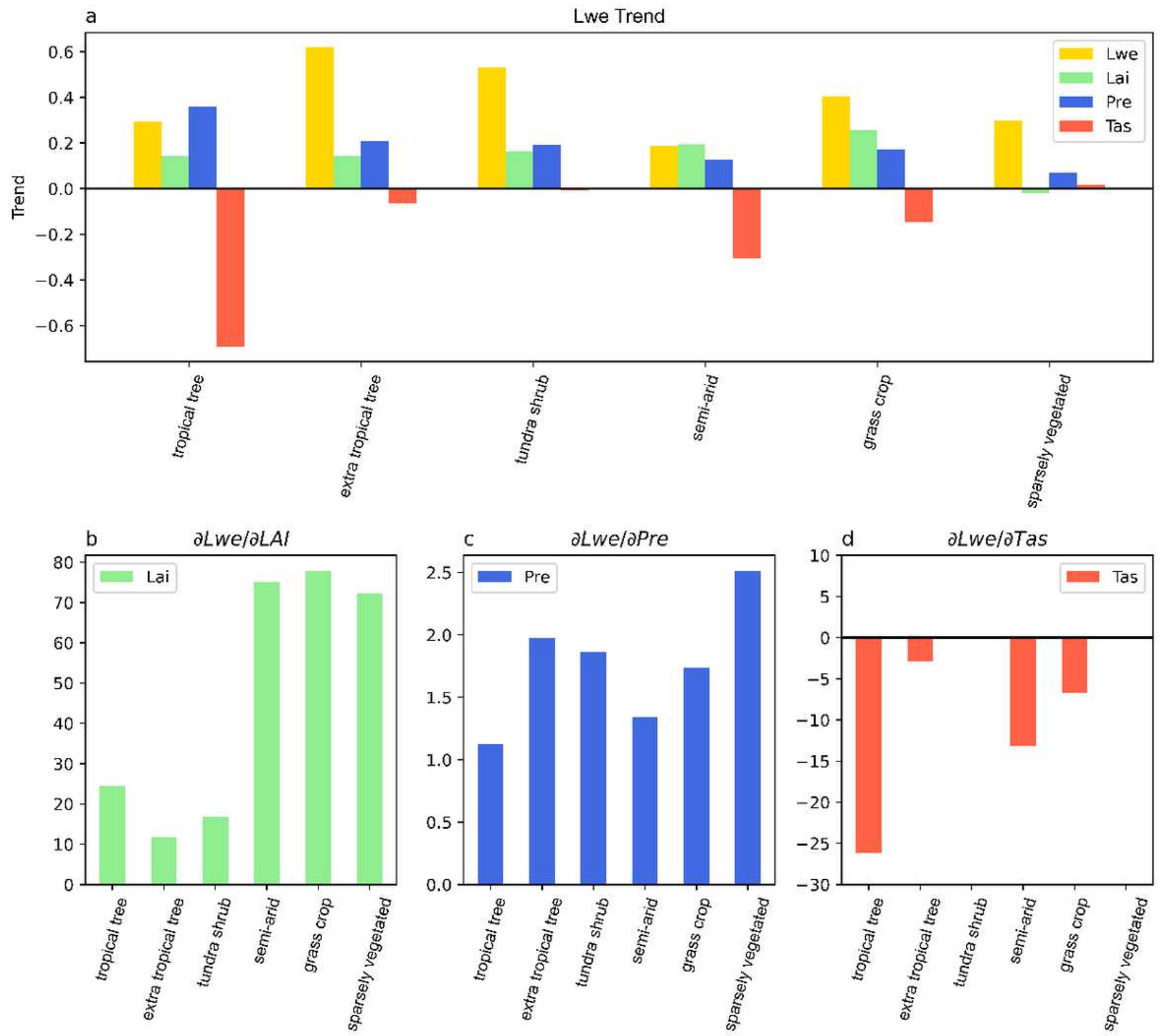

Figure 9

Effects of the long-term trends in LAI, T, P on the TWS (GRACE-REC) trend (a), sensitivity of TWS (GRACEREC) on LAI (b), P (c), T (d), all of 6 land cover classes: tropical forest, extra-tropical forest, semi-arid ecosystems, tundra and arctic shrub land, grasslands and crops, and sparsely vegetated. 


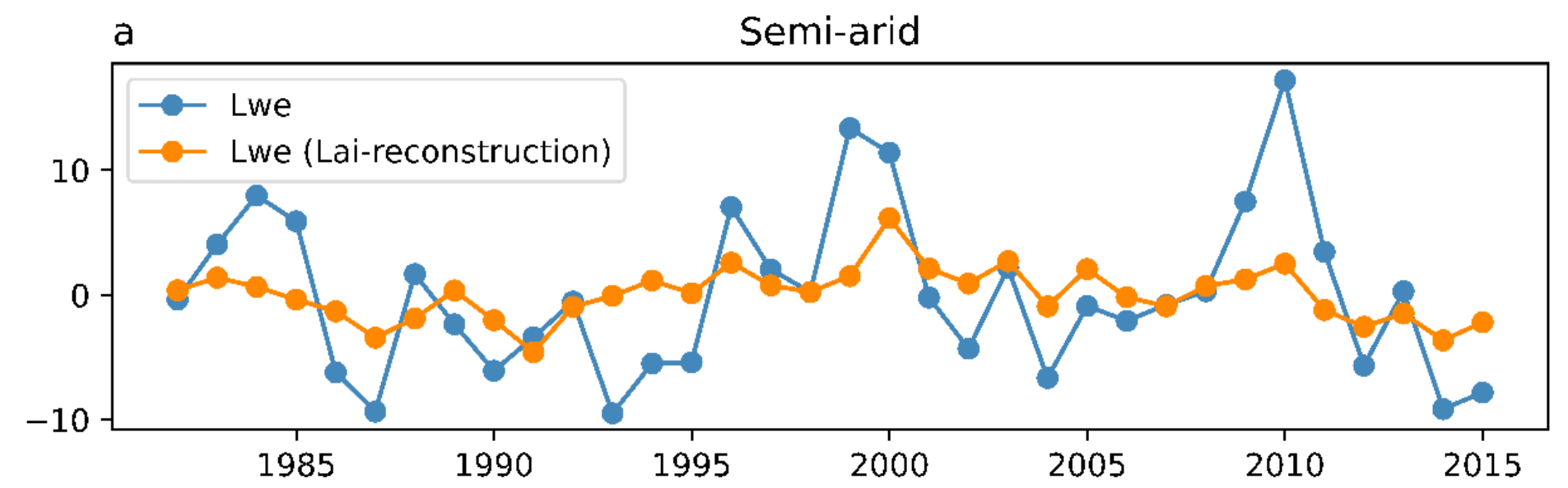

b

Grass crop

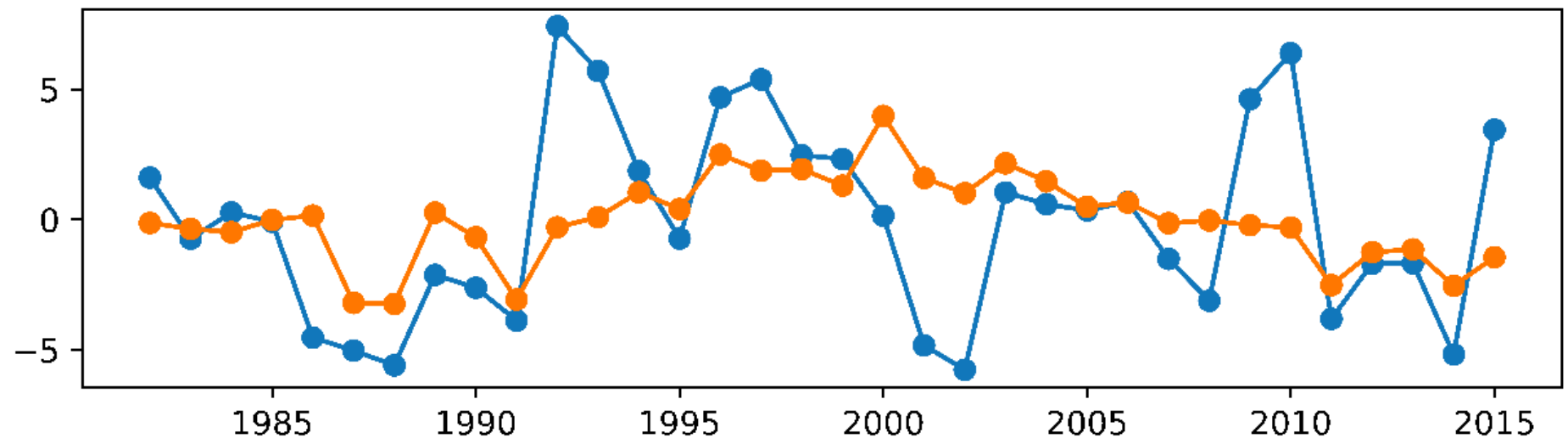

$\mathrm{C}$

Sparsely vegetated

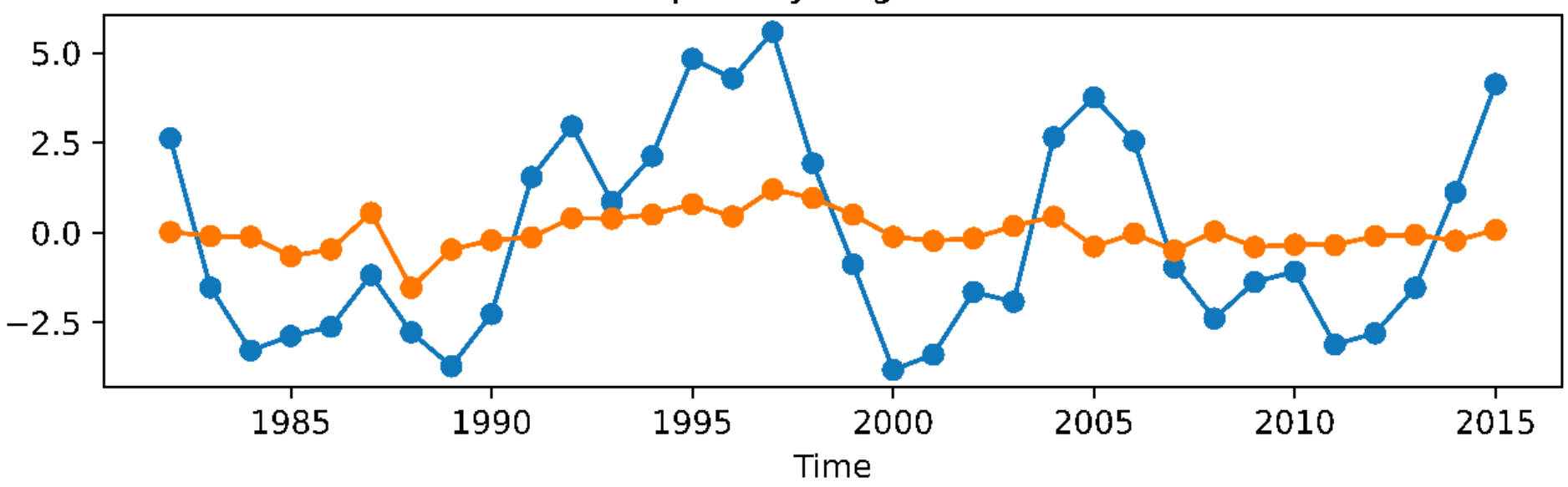

Figure 10

Temporal variations in TWS (GRACE-REC), LAl-related TWS (LAl-reconstructed TWS) computed for the 1982-2016 period for semi-arid (a), grasslands crops (b), and sparsely vegetated (c) regions. 


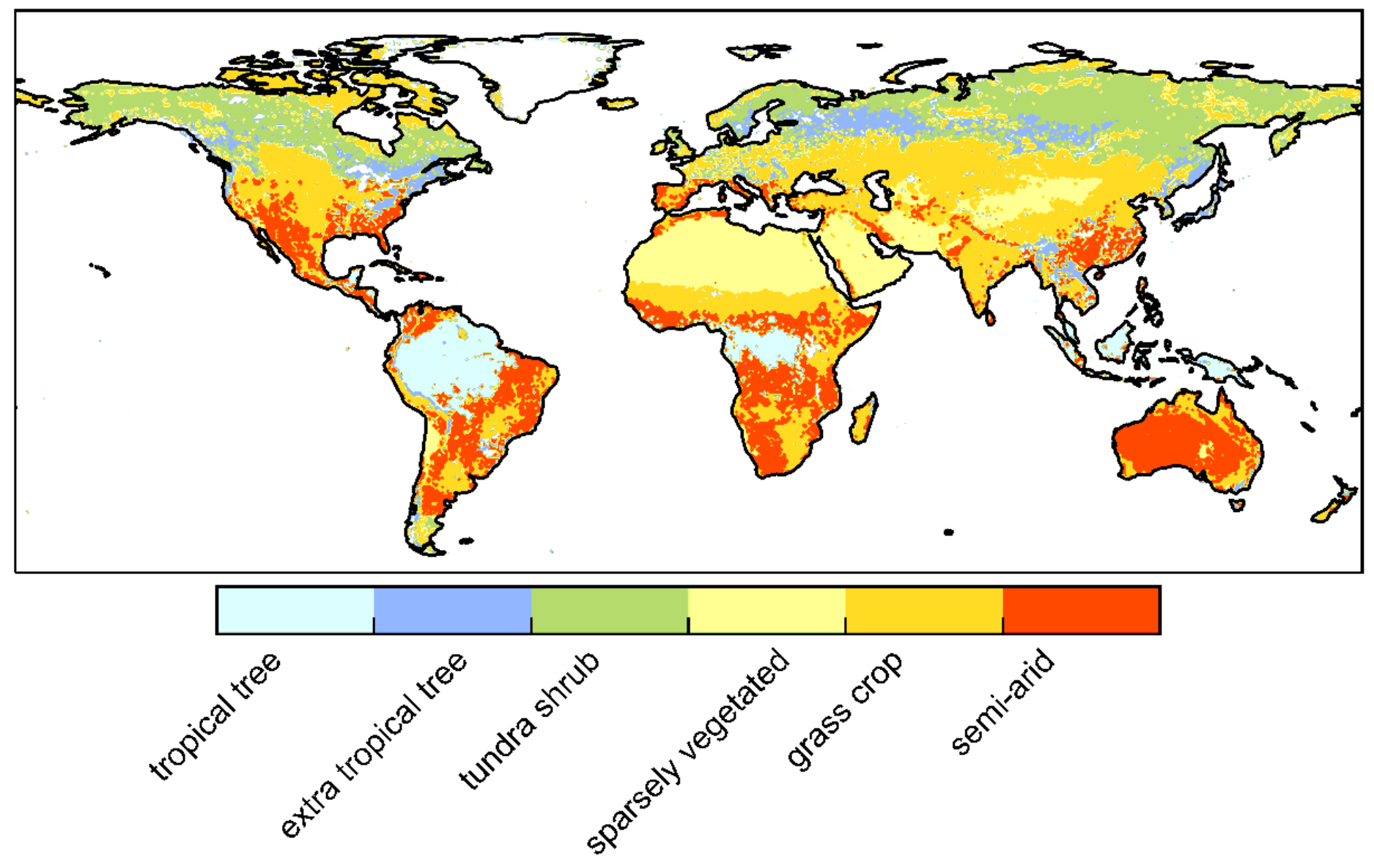

Figure 11

Map of 6 land cover classes: tropical forest, extra-tropical forest, semi-arid ecosystems, tundra and arctic shrub land, grasslands and crops, and sparsely vegetated. Note: The designations employed and the presentation of the material on this map do not imply the expression of any opinion whatsoever on the part of Research Square concerning the legal status of any country, territory, city or area or of its authorities, or concerning the delimitation of its frontiers or boundaries. This map has been provided by the authors.

\section{Supplementary Files}

This is a list of supplementary files associated with this preprint. Click to download.

- SupplementaryFigures.docx 